\title{
HIDROQUÍMICA DOS SISTEMAS AQUÍFEROS BAURU E GUARANI NA REGIÃO METROPOLITANA DE BAURU (SP)
}

\author{
HYDROGEOCHEMISTRY OF THE BAURU AND GUARANI AQUIFER SYSTEMS IN \\ THE METROPOLITAN REGION OF BAURU (SP)
}

\author{
Sueli Roberta da Silva ${ }^{1}$, Hung Kiang Chang ${ }^{2}$
}

\begin{abstract}
RESUMO Neste estudo procedeu-se à caracterização hidroquímica de amostras de águas coletadas em poços de abastecimento da área urbana de Bauru. Os poços utilizados apresentam seção filtrante nos sistemas aquíferos Bauru e Guarani que ocorrem na área. Os resultados assinalam que as águas do Sistema Aquífero Bauru (SAB) são predominantemente ácidas e bicarbonatadas cálcicas, provavelmente devido à dissolução de carbonatos e à monossialitização de feldspatos, enquanto as águas do Sistema Aquífero Guarani (SAG) apresentam-se predominantemente básicas e bicarbonatadas sódicas, com provável precipitação de carbonatos e reações de troca catiônica. Essas diferenças mostram que esses sistemas aquíferos são independentes na área urbana de Bauru, mesmo onde o SAB encontra-se assentado diretamente sobre o SAG. Contudo, em quatro poços do $\mathrm{SAG}$, o pH e as concentrações de cálcio, nitrato e cloreto são similares aos obtidos para as águas do SAB, denotando que nesses locais os sistemas aquíferos estão interconectados. Tal interconexão pode ser fruto das características de construção dos poços, o que ocasionaria contaminação cruzada, com infiltração através do pré-filtro. Nota-se ainda que as águas do SAB apresentam concentrações maiores de nitrato e cloreto na porção central da área de estudo, provavelmente como resultado de influência antrópica.
\end{abstract}

Palavras chave: aquífero Bauru, aquífero Guarani, hidroquímica.

\begin{abstract}
This study presents the results of hydrochemical characterization of groundwater based on tubular well samples collected in urban area of Bauru municipality. These wells have filters installed in Bauru Aquifer System (SAB) and Guarani Aquifer System (SAG). Groundwater from SAB is predominantly acid and of calcium-bicarbonate type and its composition is probably related to carbonate dissolution and feldspar hydrolysis. SAG groundwater is predominantly basic and sodium-bicarbonate type and its composition is probably related to carbonate precipitation and cation exchange. These differences in chemical composition show that the aquifers systems are not interconnected in the study area, despite the fact that the rocks of Bauru Group (SAB) lie directly upon the Botucatu and Pirambóia Formations (SAG), where Serra Geral Formation is missing. In four samples from SAG, pH values and calcium, nitrate and chloride concentrations are similar to those of SAB groundwater; suggesting connectivity between the aquifers. However, this is more likely due to cross-contamination, where infiltration occurs through well sandpack. It can be noted that nitrate and chloride concentrations are higher in the central portion of the study area, probably as a result of anthropic influence.
\end{abstract}

Keywords: Bauru aquifer, Guarani aquifer, hydrochemistry.

\section{INTRODUÇÃO E OBJETIVOS}

A disponibilidade hídrica no planeta não é homogênea, nem espacial nem sazonalmente. Dessa forma, enquanto algumas regiões podem enfrentar danos com precipitações intensas, outras podem sofrer com seca prolongada. Estas variações são mais graves quando atingem grandes populações, ou quando a população está em grande crescimento como na África sub-sahariana, no sul da Ásia e em alguns países da América do Sul e Oriente Médio (UNESCO, 2009). Somando-se a isso, a qualidade da água superficial e subterrânea tem sofrido impacto nas últimas décadas, principalmente devido ao crescimento das atividades agrícolas e industriais (IPCC, 2009). Dessa forma, o gerenciamento dos recursos hídricos é ferramenta importante para o crescimento e desenvolvimento da sociedade.

Os estudos que tratam da interação entre os sistemas hídricos atmosférico, superficial e subterrâneo têm sido de grande importância para seu gerenciamento. A explotação da água subterrânea, isoladamente ou como complemento à explotação dos recursos hídricos superficiais, tem vantagens tais como a menor variabilidade na disponibilidade em relação às variações sazonais e o menor custo para tratamento e distribuição. Porém, o mau gerenciamento e/ou problemas construtivos na instalação dos poços tubulares podem acarretar a contaminação e/ou o esgotamento desse recurso.

O Brasil possui cerca de $12 \%$ da disponibilidade hídrica do planeta. No estado de São Paulo, o abastecimento hídrico utiliza-se da água subterrânea, de forma total ou em conjunto com água superficial, em mais de $70 \%$ das cidades. Os sistemas aquíferos Bauru e Guarani, objetos deste estudo, estão presentes na porção centro-oeste do estado e correspondem a aproximadamente $75 \%$ de sua área (ANA, 2010).

Em grande parte do centro-oeste do estado, o Sistema Aquífero Bauru (SAB) apresenta-se predominantemente livre e o Sistema Aquífero Guarani (SAG) apresenta-se confinado pelos basaltos da Formação Serra Geral, acima, e

LEBAC - Laboratório de Estudos de Bacias - UNESP - Universidade Estadual Paulista, (sueli_rs@yahoo.com.br).

LEBAC - Laboratório de Estudos de Bacias - UNESP - Universidade Estadual Paulista, (chang@rc.unesp.br) 
pelas formações pelíticas da Formação Teresina, sotoposta.

Diversos estudos foram realizados no estado de São Paulo, visando ao melhor conhecimento do SAB (FERNANDES, 1998; BARISON, 2003; STRADIOTO, 2007) e do SAG (SILVA, 1982; CAMPOS, 1987; MENG e MAYNARD, 2001; SRACEK E HIRATA, 2002; GESICKI, 2007). O presente estudo hidrogeoquímico do SAG e do SAB no município de Bauru teve por objetivos a caracterização hidroquímica de suas águas, a relação da composição química dessas águas com o arcabouço geológico (interação rocha-fluido) e a avaliação de uma possível inter-relação entre esses dois sistemas aquíferos.

\section{ÁREA DE ESTUDO}

A área de estudo tem aproximadamente $175 \mathrm{~km}^{2}$, correspondente à área urbana do município de Bauru, e localiza-se na porção central do estado, a cerca de 350 km da capital de São Paulo (Figura 1), tendo como principal via de acesso a Rodovia Marechal Rondon (SP 300).

O município possui aproximadamente 380000 habitantes (IBGE, 2007) e abrange as bacias hidrográficas dos rios Bauru e Batalha (UGRHI 13 e 16) (Figura 1), afluentes da margem esquerda do rio Tietê. Aproximadamente $60 \%$ do abastecimento público de água para consumo provêm das águas subterrâneas do SAG (Formações Botucatu e Pirambóia), e cerca de $40 \%$ do Rio Batalha. A área urbana de Bauru conta ainda com aproximadamente 300 poços tubulares que explotam água subterrânea do SAB (Formação Adamantina) para uso particular (GIAFFERIS e OLIVEIRA, 2007).

A coluna estratigráfica (Figura 2) da área mostra as formações cretáceas (Grupo Bauru) assentadas, em contato discordante, sobre as formações Serra Geral, Botucatu ou Pirambóia, dependendo de sua localização, conforme Figura 3. O SAG é constituído pelas formações Botucatu e Pirambóia do Grupo São Bento, com o topo a profundidades que variam de 58 m a 193 m, na área urbana de Bauru, considerando os dados de outorga dos poços tubulares contemplados nesta pesquisa. Na região, o SAG está coberto pelas formações Adamantina e Marília do Grupo Bauru. Conforme detectado em perfis geofísicos por Cavaguti e Paula e Silva (1994), na região de Bauru ocorre predominantemente a Formação Adamantina, cuja base é composta por sedimentos pelíticos.

\section{GEOLOGIA DO SAB E DO SAG}

A Formação Pirambóia, conforme definição de SOARES (1975), compreende uma sucessão predominantemente arenosa, de granulação fina a média, teor de argila crescente em direção à base, com ocorrência local de arenitos grossos a conglomeráticos e presença de intercalações pouco espessas de lamitos avermelhados, mais frequentes nas porções basais. Apresenta maturidade textural e mineralógica, matriz secundária composta por argilas infiltradas, cimentação por óxidos de ferro, argilominerais e calcita, recrescimentos de quartzo e feldspato, quartzo como mineral predominante e até $10 \%$ de feldspatos detríticos (WU E CAETANO-CHANG, 1992). O ambiente deposicional é interpretado como eólico úmido, com fácies de ambiente fluvial (CAETANO-CHANG, 1997) ou como eólico úmido com fácies fluvial e costeira (DONATI ET AL., 2001; GESICKI, 2007).

A Formação Botucatu, conforme definição de SOARES (1975), compreende um pacote de arenitos avermelhados, muito finos a finos, friáveis, quartzosos, bem arredondados, bem selecionados, de origem eólica. Segundo WU E CAETANO-CHANG (1992) E GESICKI (2007), a Formação Botucatu é composta principalmente por quartzo-arenitos com alta maturidade textural e mineralógica, sendo comum a cimentação por óxido-hidróxidos de ferro, esmectita e calcita.

A deposição do Grupo Bauru teve início no Cretáceo Superior, em ambiente árido e semi-árido (FERNANDES, 1992). Esse grupo é composto, no estado de São Paulo, pelas formações Marília, Adamantina, Araçatuba, Birigui, Santo Anastácio, Caiuá, Pirapozinho (PAULA E SILVA, 2003). A litologia dominante nessa unidade é composta por arenitos, predominantemente quartzo-arenitos e, secundariamente, sublitarenitos, subarcóseos e lito-arenitos (BARISON, 2003; STRADIOTO, 2007). Segundo Barison (2003), que estudou a porção meridional do SAB no estado de São Paulo, a matriz dos arenitos estudados É constituída predominantemente pelos argilominerais caulinita, ilita e montmorilonita e corresponde a aproximadamente $20 \%$ da rocha. Em estudos na região sudoeste do estado de São Paulo, Stradioto (2007) verificou que a matriz argilosa dos arenitos, composta predominantemente por ilita e montmorilonita, ocorre em quantidades menores que $10 \%$. A presença de caulinita autigênica tem ampla distribuição, com preenchimento de poros secundários e recobrimento de grãos. É comum a associação com a cimentação ferruginosa (CAMPOS, 1987).

Na cidade de Bauru afloram as unidades litoestratigráficas Marília e Adamantina (PAULA E SILVA E CAVAGUTI, 1994). A Formação Marília (Membro Echaporã), sobreposta à Formação Adamantina por contato interdigitado e abrupto, é composta por arenitos grossos a conglomeráticos, com teor de matriz variável, rico em feldspatos e raras camadas de lamitos vermelhos e calcários (SOARES ET AL., 1980). Os argilominerais mais comuns são ilita e esmecticta (FERNANDES, 1992). Em estudos petrográficos realizados por FERNANDES (1992) e BARISON (2003), foram observados processos de dissolução de feldspatos potássicos com geração de argilominerais do tipo montmorilonita, que gradam para ilita; também foi identificada a presença de paligorsquita. Em subsuperfície, tem composição predominantemente arenosa, com intercalações de material pelítico (PAULA E SILVA, 2003). Segundo SOARES ET AL. (1980), FERNANDES (1992, 1998) E PAULA E SILVA (2003), Foi depositada em ambiente de leque aluvial. A Formação Adamantina segundo SOARES ET AL. (1980), é composta por um conjunto de fácies cuja principal característica é a pre- 


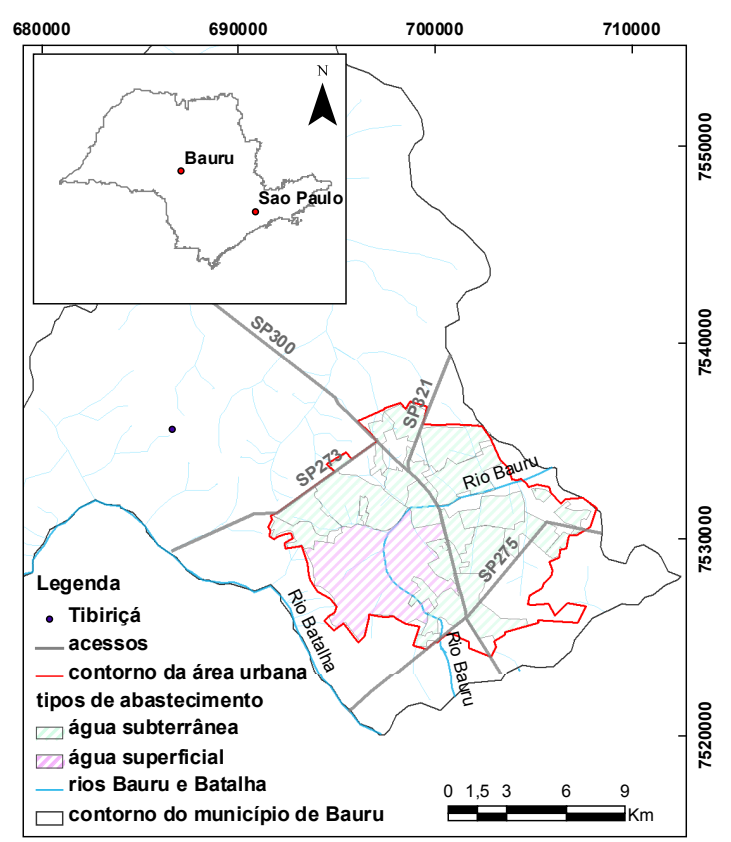

Figura 1. Localização da área de estudo Figure 1. Location map of the study area

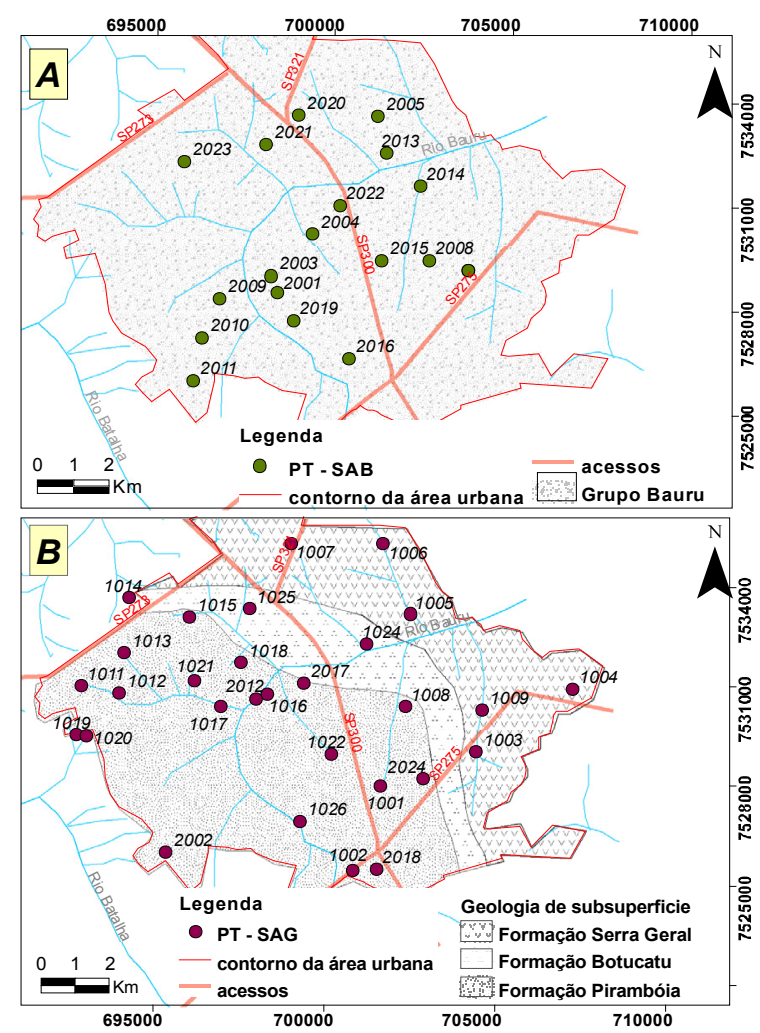

sença de bancos de arenitos com espessuras que variam de $2 \mathrm{~m}$ a $20 \mathrm{~m}$, granulação fina a muito fina, com variabilidade regional, e conjuntos litológicos distintos mais ou menos localizados. Esses arenitos exibem estratificação cruzada e se alternam com camadas de lamitos, siltitos e arenitos lamíticos com acamamento plano-paralelo e frequentes marcas onduladas e microestratificações cruzadas. Os feldspatos se

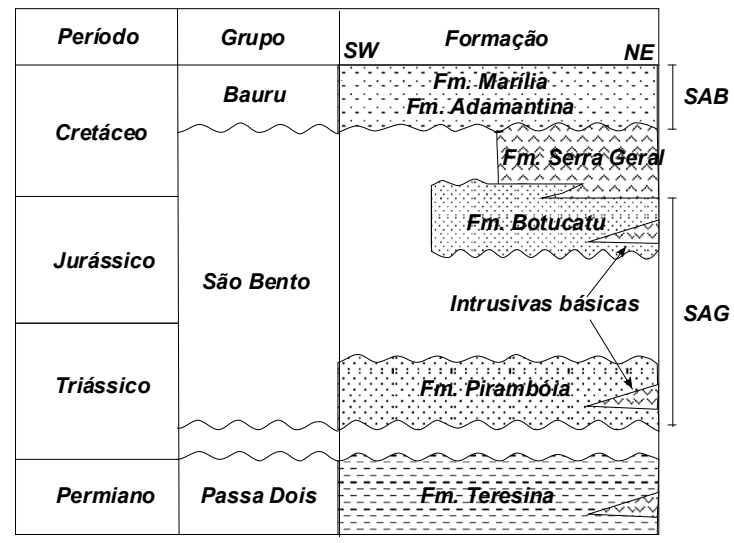

Figura 2. Coluna estratigráfica da área de estudo Figure 2. Stratigraphical chart of study area

Figura 3. Localização dos poços de abastecimento utilizados no estudo. A: Mapa Geológico da área de estudo e localização de poços que captam água do SAB. B. Distribuição de unidades subjacentes em contato com o $\mathrm{SAB}$ e localização dos poços que captam água do SAG.

Figure 3. Location map of the wells in the study area. AGeological map showing wells producing from SAB. B- Subcrop map of the stratigraphic units at the base of SAB. Wells from this map produce from SAG. apresentam em quantidades sempre inferiores a $12 \%$, com porcentagem média estimada de 1,8\% (BARISON, 2003), constituídos principalmente por ortoclásio, microclinio e plagioclásio, ocorrendo desde inalterados até totalmente alterados. É verificada a dissolução com coatings de montmorilonita, incluindo porosidade móldica com recobrimento por argilominerais, dentre os quais montmorilonita e ilita. 


\section{HIDROQUÍMICA}

As águas do SAG NO ESTADO DE SÃO PAULO foram classificadas por SILVA (1983) como bicarbonatadas cálcicas a bicarbonatadas sódicas. Essa autora identificou três fácies hidroquímicas diferenciadas em relação à distância da zona de recarga e à profundidade do aquífero, quais sejam: predomínio de águas bicarbonatadas magnesianas e cálcio-magnesianas, águas bicarbonatadas cálcicas a cálcio-magnesianas e águas bicarbonatadas sódicas. A partir desses dados, MENG E MAYNARD (2001) subdividiram o SAG em três grupos de águas subterrâneas, relacionadas à proximidade da área de afloramento ou à profundidade do aquífero, e identificaram como componentes químicos dominantes: $\mathrm{SiO}_{2}$ para as águas da área de afloramento, $\mathrm{Ca}^{2+}$ e $\mathrm{HCO}_{3}^{-}$para as águas da área intermediária, e $\mathrm{Na}^{+}, \mathrm{CO}_{3}{ }^{2-}$ e $\mathrm{SO}_{4}{ }^{2-}$ para as águas da área confinada.

ROCHA ET AL. (1982) propuseram a subdivisão do SAB em duas unidades hidrogeológicas distintas, no estado de São Paulo. Uma unidade, caracterizada como fortemente bicarbonatada cálcica a cálcio-magnesiana, corresponde às formações Adamantina e Marília, e outra, fracamente bicarbonatada cálcio-magnesiana, corresponde às formações Santo Anastácio e Caiuá. Foram verificados também, por esses autores, teores salinos elevados, fortemente cálcicos, associados aos domínios geomorfológicos dos planaltos e espigões que são, via de regra, áreas de ocorrência dos arenitos da parte superior da Formação Adamantina e da Formação Marília. A evolução hidrogeoquímica $\mathrm{Ca} \rightarrow$ $\mathrm{Mg} \rightarrow \mathrm{Na}$, de montante para jusante, é observada nos principais rios interiores que cortam rochas do Grupo Bauru.

CAMPOS (1987), COELHO (1996) E BARISON (2003) confirmaram os dois tipos hidroquímicos identificados por ROCHA ET AL. (1982). SEGUNDO ESSES AUTORES, AS ÁGUAS DO SAB APRESENTAM teores salinos baixos, marcados fortemente pela presença dos íons $\mathrm{HCO}_{3}^{-}, \mathrm{Ca}^{2+}$ e $\mathrm{Mg}^{2+}$. Estes íons apresentam, segundo esses estudos, forte correlação com os valores de $\mathrm{pH}$ e condutividade elétrica e com a evolução hidrogeoquímica regional no sentido nordeste para sudoeste, acompanhando a resultante dos fluxos da água subterrânea em direção à confluência dos rios Paraná e Paranapanema.

\section{MATERIAIS E MÉTODOS}

Foram coletadas amostras de água subterrânea de 29 poços de abastecimento que captam água do Sistema Aquífero Guarani e de 20 poços que captam água do Sistema Aquífero Bauru. Os perfis construtivo e geológico dos poços foram obtidos no Departamento de Águas e Esgotos de Bauru e no Departamento de Águas Esgotos e Energia de Araraquara. A localização dos poços de abastecimento utilizados para a amostragem da água subterrânea na área urbana do município é apresentada na figura 3.

As amostras foram coletadas na saída do poço, antes da fluoretação e cloração, e após bombeamento de alguns minutos para a retirada da água porventura presente nas tubulações. Durante a coleta, foram feitas medições dos parâmetros pH, temperatura, Eh e condutividade elétrica com eletrodos da marca ORION série 3-star.

Para envio ao laboratório, as alíquotas para análise de cátions foram previamente filtradas com filtro 0,45 $\mu \mathrm{m}$ Milipo$\mathrm{re}^{\circledR}$ e preservadas com ácido nítrico e sob refrigeração. Para as análises de ânions, a preservação foi somente sob refrigeração.

A quantificação dos íons foi realizada pelo laboratório de Hidroquímica da UNESP, em Rio Claro. Os cátions sódio e potássio foram determinados com uso de espectrofotometria de absorção atômica; os cátions silício, magnésio, cálcio, estrôncio, zinco, fósforo, chumbo, cobalto, cádmio, níquel, manganês, ferro, cromo, alumínio, cobre e bário foram analisados por espectrofotometria de emissão atômica, com fonte de plasma de argônio induzido indutivo; a alcalinidade (em $\mathrm{HCO}_{3}{ }^{-}$) foi obtida por titulação; os íons nitrato e sulfato e os ânions flúor e o cloreto foram determinados por cromatografia de íons.

Para o tratamento dos dados foi utilizado o programa Phreeq C (PARKHURST e APPELO, 1999) para a especiação hidroquímica, e o programa Rockworks $99^{\circledR}$, para a confecção do diagrama de Piper.

\section{RESULTADOS}

Os resultados das análises químicas dos cátions e ânions, incluindo o erro do balanço iônico, das amostras coletadas em poços de abastecimento do município de Bauru (Tabela 1), indicam que a água subterrânea do SAG é predominantemente bicarbonatada sódica, enquanto a água subterrânea do SAB é predominantemente bicarbonatada cálcica (Figura 4). Entretanto, verifica-se que algumas amostras provenientes de poços que captam água do SAG (amostras 1004, 1009, 1012 e 2012) são bicarbonatadas cálcicas e outras provenientes de poços que captam água do SAB (amostras 2010 e 2014) são bicarbonatadas sódicas.

A partir de avaliação estatística descritiva (Tabela 2) verifica-se que o SAG apresenta $\mathrm{pH}$ predominantemente básico, com valores entre 5,92 e 9,82 (média de 9,18), condutividade elétrica entre $74,51 \mu \mathrm{S} / \mathrm{cm}$ e $278,59 \mu \mathrm{S} / \mathrm{cm}$ (média de $137,31 \mu \mathrm{S} / \mathrm{cm}$ ), concentrações médias para bicarbonato, cálcio, magnésio, potássio e sódio de 76,65 mg/L, 2,59 $\mathrm{mg} / \mathrm{L}, 0,18 \mathrm{mg} / \mathrm{L}, 0,32 \mathrm{mg} / \mathrm{L}$ e $30,25 \mathrm{mg} / \mathrm{L}$, respectivamente. Já o SAB apresenta pH ácido com valores entre 5,29 e 7,77 (média de 6,13), condutividade elétrica entre 26,02 $\mu \mathrm{S} /$ $\mathrm{cm}$ e $341,91 \mu \mathrm{S} / \mathrm{cm}$ (média de $116,99 \mu \mathrm{S} / \mathrm{cm}$ ) e concentrações médias para cálcio, magnésio, potássio, e sódio de 7,66 $\mathrm{mg} / \mathrm{L}, 1,99 \mathrm{mg} / \mathrm{L}, 2,44 \mathrm{mg} / \mathrm{L}$ e $1,77 \mathrm{mg} / \mathrm{L}$, respectivamente.

A relação iônica obtida a partir das médias das concentrações iônicas, em meq/L, das amostras de água do $\mathrm{SAG}$, para a área metropolitana de Bauru, é de $\mathrm{rHCO}_{3}^{-}>>\mathrm{rNO}_{3}^{-}>\mathrm{rCl}^{-}>\mathrm{rSO}_{4}^{-2}$ para os ânions, e de $\mathrm{rNa}^{+}>>\mathrm{rCa}^{+2}>\mathrm{rMg}^{+2}>\mathrm{rBa}^{2+}$ para os cátions (Figura 5). 


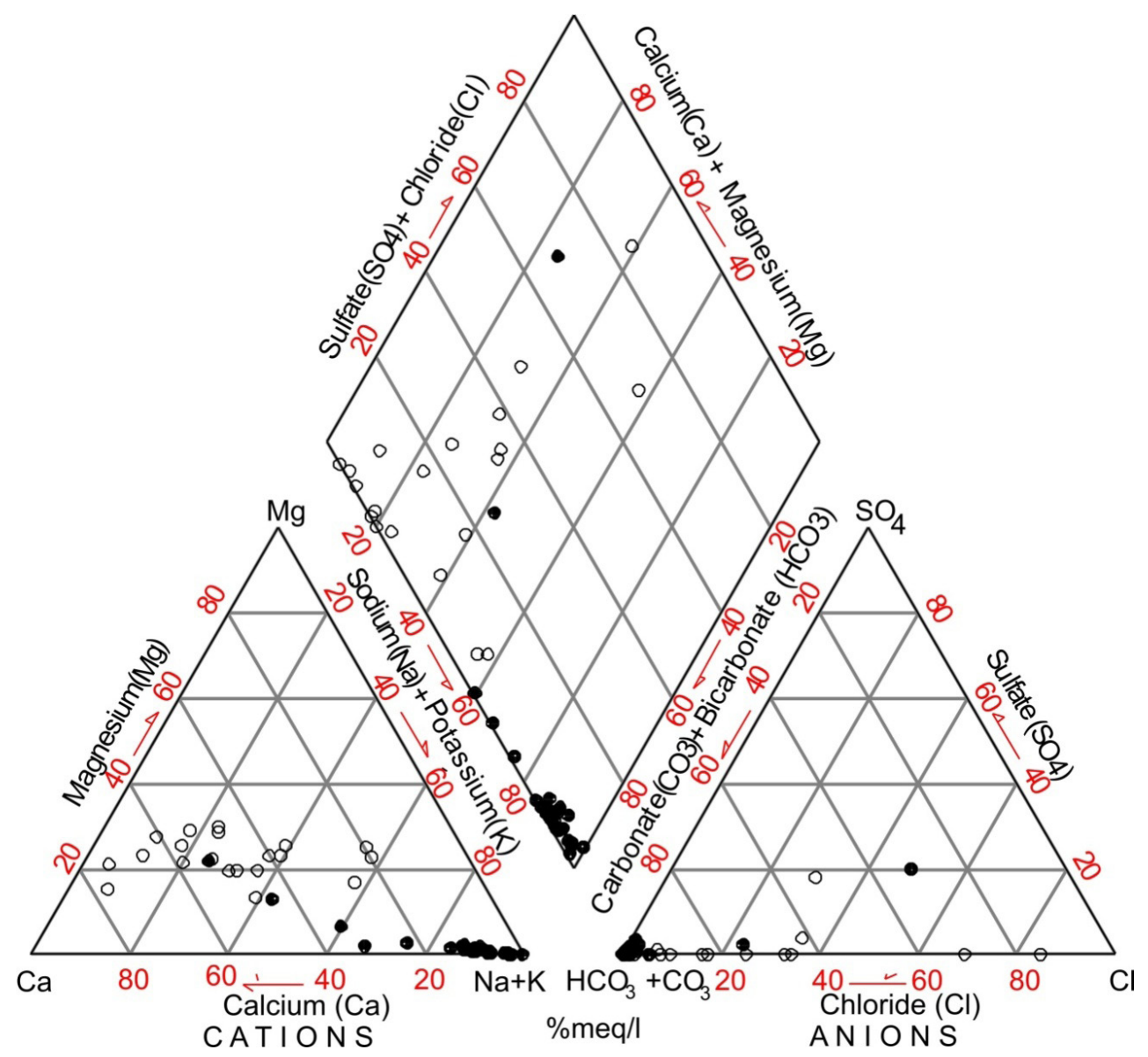

Figura 4. Diagrama de Piper - Sistema Aquífero Guarani (amostras identificadas como círculo cheio) e Sistema Aquífero Bauru (amostras identificadas como círculo vazado).

Figure 4. Piper diagram - Guarani Aquifer System (dark circle) and Bauru Aquifer System (open circle)

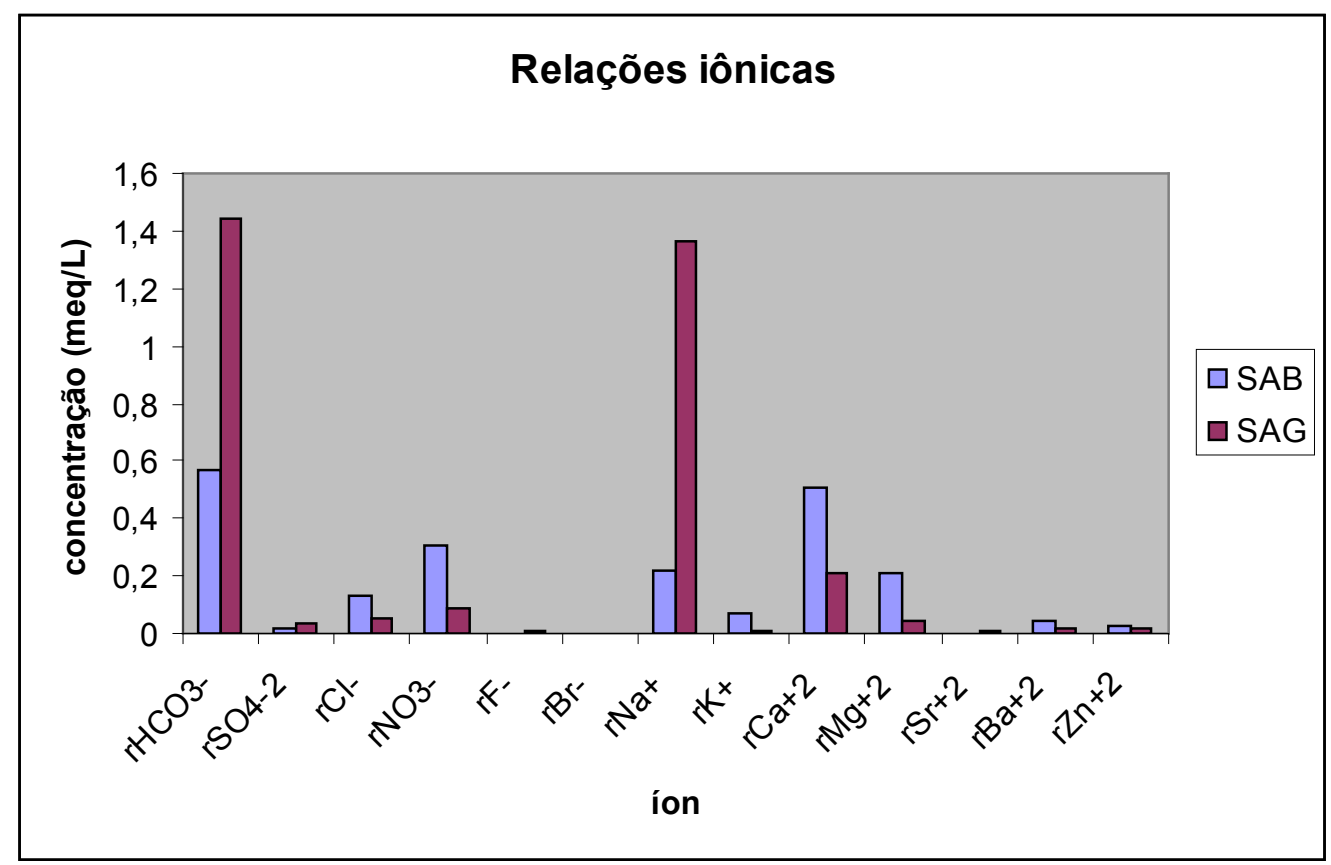

Figura 5. Valores médios das concentrações dos íons das águas subterrâneas do SAG e SAB Figure 5. Average ions concentrations in groundwater of SAG and SAB 


\begin{tabular}{|c|c|c|c|c|c|c|c|c|c|c|c|c|c|c|c|c|c|c|c|c|c|c|c|c|c|}
\hline $\bar{\varangle}$ & ' & ' & ' & ' & ' & ' & $\begin{array}{l}0 \\
0 \\
0 \\
0\end{array}$ & , & ' & ' & $\mid \begin{array}{c}\tilde{o} \\
\tilde{\delta} \\
0\end{array}$ & $\mid \begin{array}{l}12 \\
0 \\
0 \\
0\end{array}$ & & 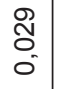 & ' & 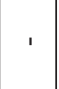 & $\begin{array}{l}\hat{L} \\
\vdots \\
0\end{array}$ & & $\begin{array}{l}\bar{\delta} \\
0 \\
0\end{array}$ & ס̊ & $\Sigma_{0}$ & ' & & ' & \\
\hline $\bar{\omega}$ & $\stackrel{m}{\infty}$ & $\begin{array}{c}0 \\
\infty \\
\infty \\
\infty\end{array}$ & $\begin{array}{l}\hat{N} \\
\wedge\end{array}$ & $\stackrel{\stackrel{\sim}{N}}{\stackrel{N}{\sim}}$ & $\begin{array}{l}\stackrel{\infty}{\stackrel{2}{\sim}} \\
\stackrel{2}{2}\end{array}$ & $\stackrel{\mathscr{S}}{\sim}$ & $\begin{array}{l}0 \\
2 \\
\infty^{-}\end{array}$ & $\underset{\stackrel{R}{R}}{\stackrel{B}{\sim}}$ & $\stackrel{\mathscr{L}}{\wedge}$ & $\stackrel{\Delta}{F}$ & $\mid \begin{array}{l}\infty \\
\infty \\
\infty\end{array}$ & $\begin{array}{l}\hat{\alpha} \\
\infty\end{array}$ & $\stackrel{m}{\kappa}$ & $\begin{array}{l}\hat{m} \\
\tilde{\omega}\end{array}$ & $\begin{array}{l}\stackrel{L}{N} \\
\infty \\
\infty\end{array}$ & $\begin{array}{l}\stackrel{J}{S} \\
\sim\end{array}$ & $\begin{array}{l}\mathscr{L} \\
\infty \\
\infty\end{array}$ & 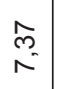 & $\frac{\hat{\sigma}}{\infty}$ & 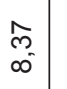 & $\begin{array}{l}\text { న } \\
\delta_{\infty}^{-}\end{array}$ & $\frac{\nabla}{\infty}$ & $\stackrel{\substack{f \\
r}}{r}$ & & $\begin{array}{l}\text { ల్ } \\
\infty \\
\infty\end{array}$ \\
\hline$\frac{\pi}{z}$ & $\begin{array}{l}\text { s. } \\
\text { ș }\end{array}$ & 今ं & $\overline{\widetilde{N}}$ & $\begin{array}{l}50 \\
0 \\
0\end{array}$ & $\begin{array}{l}\llcorner \\
\infty^{\circ} \\
N\end{array}$ & $\begin{array}{l}\infty \\
\infty^{0} \\
N\end{array}$ & $\overline{\bar{m}}$ & 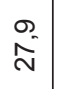 & $\stackrel{\sim}{\stackrel{N}{N}}$ & $\begin{array}{l}\bar{N} \\
\bar{N}\end{array}$ & $\begin{array}{l}\infty \\
0^{-}\end{array}$ & $\stackrel{L}{\infty}$ & $\begin{array}{l}\stackrel{0}{ } \\
\tilde{N}^{0}\end{array}$ & $\begin{array}{l}\infty \\
\mathcal{F}\end{array}$ & $\begin{array}{l}N \\
\tilde{\rho} \\
0\end{array}$ & $\overline{\bar{\rho}}$ & $\begin{array}{l}0 \\
0 \\
0^{\circ}\end{array}$ & $\hat{\tilde{N}}$ & $\begin{array}{l}\stackrel{\sigma}{0} \\
\phi^{\circ}\end{array}$ & $\stackrel{\mathscr{m}}{\stackrel{m}{m}}$ & 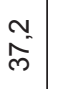 & \begin{tabular}{l|l}
$\infty$ \\
$\stackrel{\sim}{\tilde{N}}$
\end{tabular} & $\begin{array}{l}\infty \\
\stackrel{\infty}{0}^{\circ}\end{array}$ & $\begin{array}{l}\text { o } \\
\hat{O}^{\circ}\end{array}$ & $\widehat{N}$ \\
\hline$Y$ & so & $\begin{array}{l}\mathbb{N} \\
\text { o }\end{array}$ & $\begin{array}{l}\stackrel{2}{N} \\
0 \\
-1\end{array}$ & $\begin{array}{c}\hat{f} \\
0\end{array}$ & $\begin{array}{l}\tilde{N} \\
\tilde{O} \\
\tilde{O}\end{array}$ & $\underset{\sigma}{E}$ & ' & $\overline{0}$ & $\begin{array}{l}m \\
0 \\
0\end{array}$ & 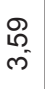 & $\frac{0}{0}$ & $\stackrel{\sigma}{0}_{0}$ & $\begin{array}{l}\stackrel{2}{c} \\
0\end{array}$ & $\begin{array}{l}\stackrel{R}{R} \\
0 \\
0\end{array}$ & $\begin{array}{l}\infty \\
0^{\infty}\end{array}$ & $\begin{array}{l}8 \\
0 \\
0\end{array}$ & $\begin{array}{l}0 \\
0^{\circ}\end{array}$ & 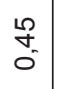 & & & $\begin{array}{l}\hat{\theta} \\
0\end{array}$ & $\begin{array}{l}\text { m. } \\
\text { m. } \\
0^{\prime}\end{array}$ & $\begin{array}{c}\hat{m} \\
\text { on } \\
0^{\prime}\end{array}$ & $\begin{array}{c}\hat{c} \\
\text { co } \\
0\end{array}$ & $\stackrel{m}{0}$ \\
\hline
\end{tabular}

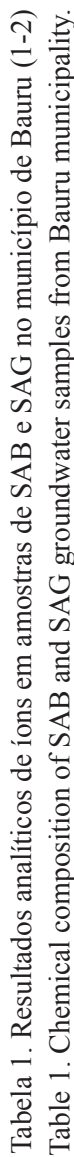

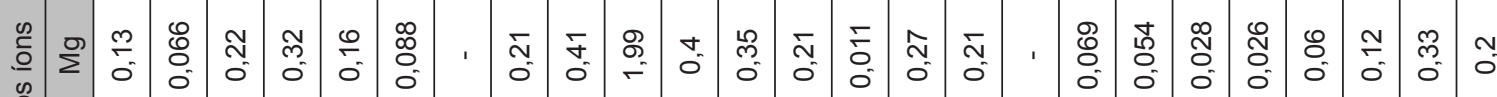

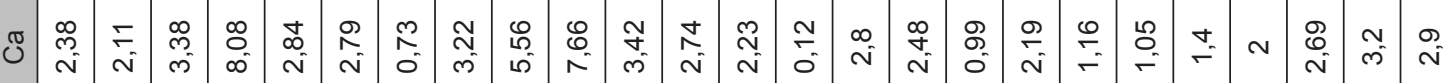

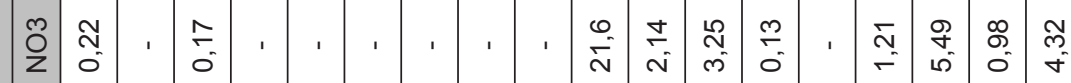

con

ז

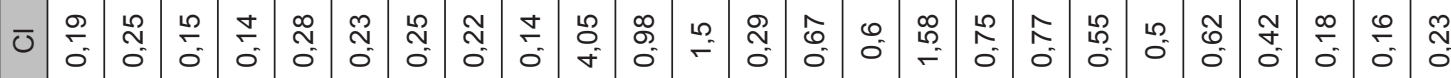

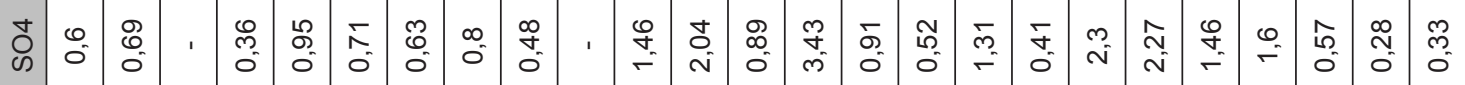

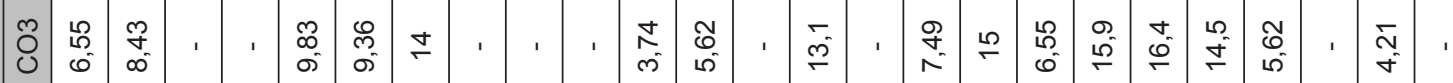

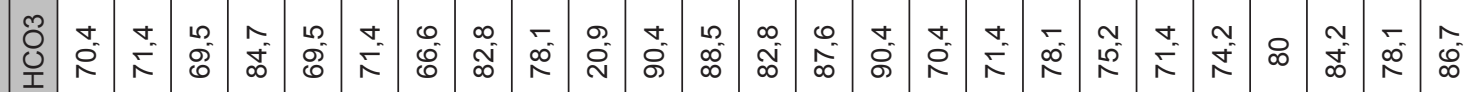

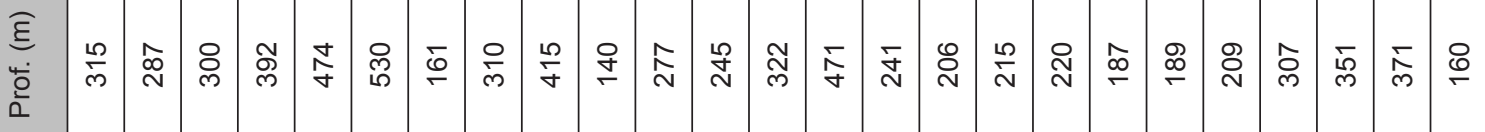

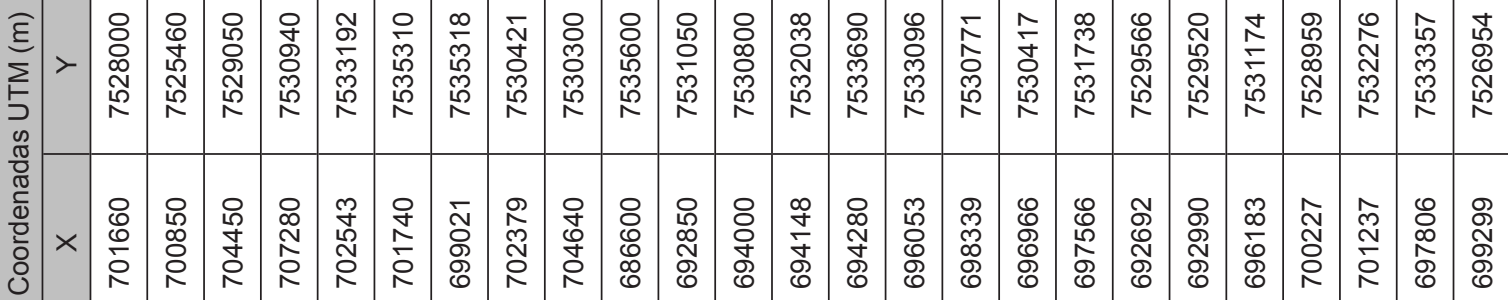

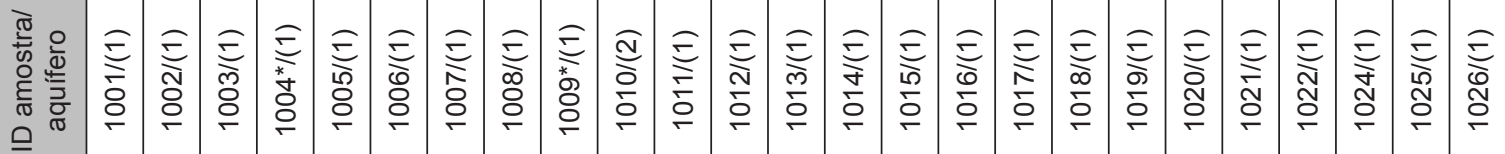




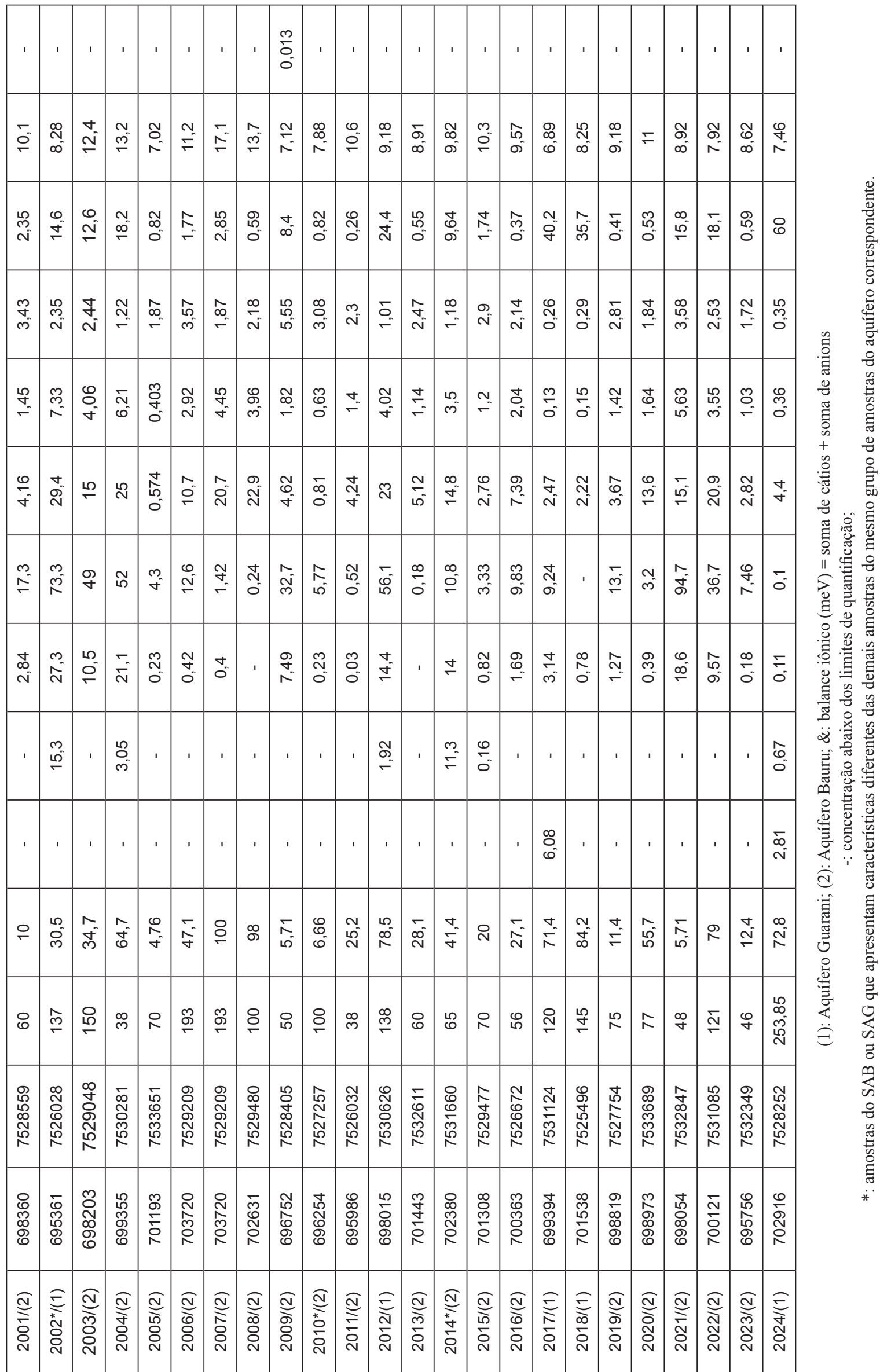




\begin{tabular}{|c|c|c|c|c|c|c|c|c|c|c|c|c|c|c|c|c|c|c|c|c|c|c|c|c|}
\hline 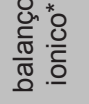 & $\frac{\nabla}{i}$ & $\begin{array}{l}\text { J } \\
0 \\
i\end{array}$ & $\begin{array}{l}8 \\
0\end{array}$ & É & $\begin{array}{l}8 \\
0 \\
0 \\
1\end{array}$ & $\begin{array}{c}\bar{E} \\
\bar{c} \\
\end{array}$ & $\begin{array}{l}0 \\
\tilde{O} \\
i\end{array}$ & $\begin{array}{l}\widetilde{O} \\
0^{-}\end{array}$ & $\begin{array}{l}\tilde{O} \\
0 \\
0 \\
\end{array}$ & $\begin{array}{l}\qquad 0 \\
0 \\
0\end{array}$ & $\frac{n}{2}$ & $\begin{array}{l}\overline{0} \\
\overline{0} \\
\bar{i}\end{array}$ & $\begin{array}{l}\delta_{0} \\
0^{\circ}\end{array}$ & $\begin{array}{l}\infty \\
0 \\
0 \\
i\end{array}$ & $\begin{array}{l}\overline{0} \\
\bar{i}\end{array}$ & $\begin{array}{l}\hat{0} \\
0 \\
0 \\
1\end{array}$ & 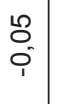 & $\begin{array}{l}\overline{0} \\
\overline{0} \\
\end{array}$ & $\begin{array}{l}\hat{o} \\
\text { o. }\end{array}$ & 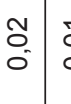 & $\begin{array}{l}\delta \\
\delta\end{array}$ & $\begin{array}{l}8 \\
0 \\
0\end{array}$ & $\begin{array}{l}8 \\
0 \\
0\end{array}$ & $\begin{array}{l}\delta \\
0 \\
0\end{array}$ \\
\hline $\bar{N}$ & & $\begin{array}{l}0 \\
0 \\
0 \\
0\end{array}$ & $\stackrel{\infty}{0}_{0}^{\infty}$ & & & $\overline{0}$ & $\begin{array}{l}\infty \\
\stackrel{\infty}{N}\end{array}$ & $\begin{array}{c}E \\
0\end{array}$ & $\begin{array}{l}\infty \\
0^{\infty}\end{array}$ & $\stackrel{\infty}{\stackrel{\infty}{\sim}}$ & 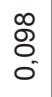 & 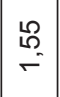 & $\begin{array}{l}5 \\
0 \\
0\end{array}$ & $\begin{array}{l}\bar{L} \\
0 \\
0\end{array}$ & $\begin{array}{l}\overline{0} \\
0 \\
0\end{array}$ & 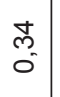 & s. & $\begin{array}{l}\text { ָे } \\
0 \\
0\end{array}$ & $\begin{array}{l}\underset{⿱}{N} \\
\text { D }\end{array}$ & 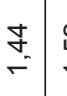 & مֵ & $\underset{\sim}{\mathbb{0}}$ & $\stackrel{\mathbb{N}}{\stackrel{5}{-}}$ & $\begin{array}{c}\sigma_{0} \\
0\end{array}$ \\
\hline के & 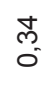 & $\underset{\widetilde{N}}{\mathbb{N}}$ & $\overline{0}$ & $\begin{array}{c}M \\
\text { O } \\
0\end{array}$ & $\begin{array}{l}\bar{m} \\
0 \\
0\end{array}$ & $\begin{array}{c}\hat{N} \\
0 \\
\vdots\end{array}$ & $\overline{0}^{\circ}$ & $\stackrel{0}{0}$ & $\begin{array}{l}\overrightarrow{0} \\
0\end{array}$ & $\begin{array}{l}\infty \\
8 \\
0 \\
0\end{array}$ & $\frac{9}{5}$ & $\frac{\infty}{0}$ & $\stackrel{m}{0}$ & $\begin{array}{l}\infty \\
\stackrel{-}{0} \\
0\end{array}$ & $\begin{array}{c}\vec{m} \\
0 \\
0\end{array}$ & $\ddot{\circ}$ & $\stackrel{\nabla}{0}$ & $\begin{array}{l}\stackrel{m}{0} \\
0 \\
0\end{array}$ & $\stackrel{m}{0}$ & 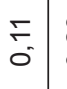 & 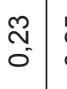 & 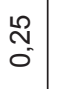 & t. & స్ \\
\hline
\end{tabular}

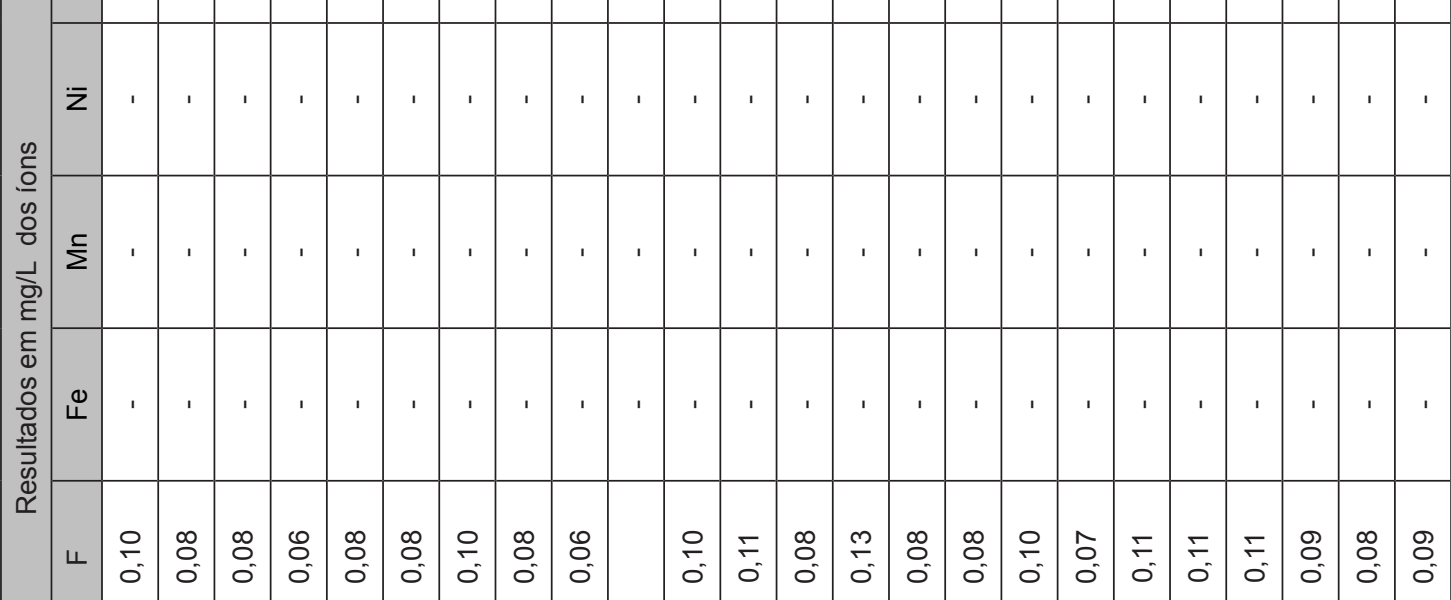

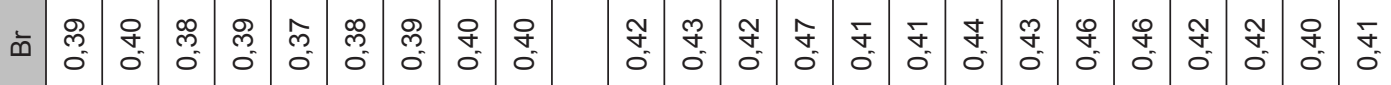

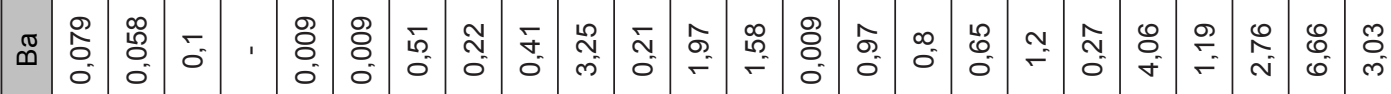

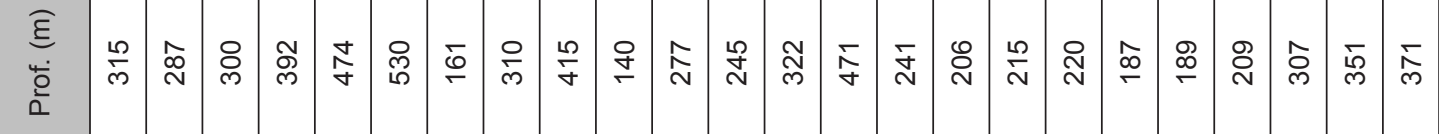

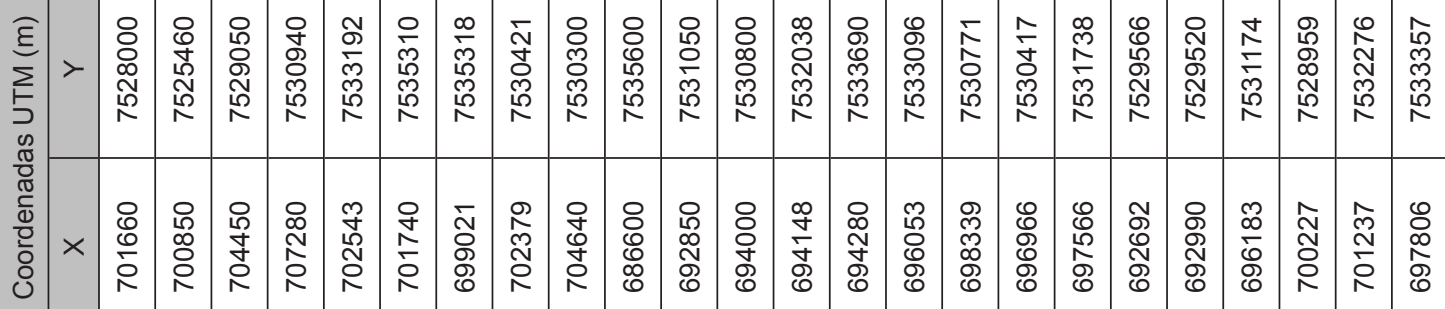

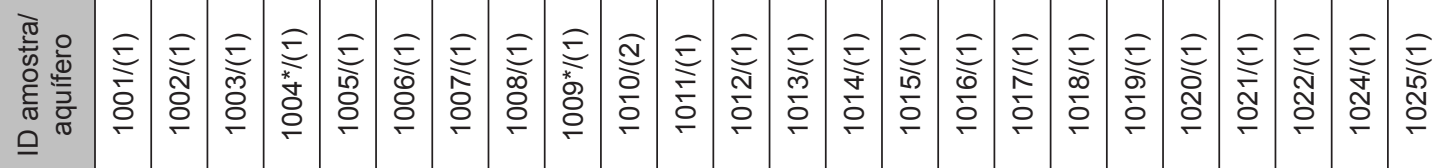




\begin{tabular}{|c|c|c|c|c|c|c|c|c|c|c|c|c|c|c|c|c|c|c|c|c|c|c|c|}
\hline $\begin{array}{l}2 \\
0 \\
0\end{array}$ & $\begin{array}{l}\infty \\
0 \\
0\end{array}$ & mo & $\frac{9}{0}$ & $\begin{array}{l}\hat{0} \\
0\end{array}$ & $\begin{array}{l}\delta \\
\delta^{-}\end{array}$ & $\begin{array}{l}\tilde{O} \\
0 \\
0\end{array}$ & $\begin{array}{l}\bar{\sigma} \\
0\end{array}$ & $\begin{array}{l}\text { ¿े } \\
\text { o }\end{array}$ & $\begin{array}{l}8 \\
0 \\
0\end{array}$ & $\begin{array}{l}8 \\
0\end{array}$ & $\begin{array}{l}\dddot{0} \\
0 \\
0\end{array}$ & \begin{tabular}{l}
$\cong$ \\
\hdashline
\end{tabular} & $\underset{\sigma}{\sigma}$ & $\begin{array}{l}20 \\
0 \\
0\end{array}$ & $\begin{array}{l}\widetilde{1} \\
\delta \\
0\end{array}$ & $\begin{array}{l}\infty \\
0^{-} \\
0\end{array}$ & $\begin{array}{c}\tilde{m} \\
0 \\
0\end{array}$ & $\begin{array}{l}\hat{N} \\
\tilde{O}\end{array}$ & $\begin{array}{l}\widetilde{D} \\
0^{-}\end{array}$ & 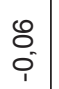 & \begin{tabular}{l} 
lo \\
\hdashline
\end{tabular} & $\begin{array}{l}\infty \\
0_{0}^{\circ}\end{array}$ & $\frac{2}{0}$ \\
\hline סֵ & $\begin{array}{c}\hat{f} \\
0\end{array}$ & \begin{tabular}{l}
$\mathbb{N}$ \\
\hdashline \\
0
\end{tabular} & 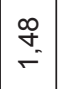 & $\begin{array}{c}\bar{m}_{0} \\
\tilde{o}^{\prime}\end{array}$ & 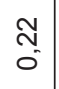 & $\begin{array}{l}\stackrel{?}{N} \\
\text { O }\end{array}$ & $\begin{array}{c}\hat{\sigma} \\
0\end{array}$ & $\underset{\sigma}{N}$ & $\mid \begin{array}{c}0 \\
\stackrel{2}{0} \\
0\end{array}$ & $\frac{N}{\tilde{0}}$ & $\begin{array}{l}\stackrel{0}{m} \\
\stackrel{-}{-}\end{array}$ & $\begin{array}{l}\stackrel{m}{m} \\
\overbrace{}^{-}\end{array}$ & $\stackrel{\circ}{=}$ & $\begin{array}{l}\text { N } \\
\text { O' }\end{array}$ & \begin{tabular}{l}
\multirow{2}{0}{} \\
0 \\
0
\end{tabular} & $\underset{\leftarrow}{\sigma}$ & $\begin{array}{c}\bar{m} \\
\sigma_{0}^{\prime}\end{array}$ & $\frac{\infty}{\leftarrow}$ & $\begin{array}{l}\mathscr{D} \\
\\
0\end{array}$ & $\stackrel{5}{\sigma}$ & $\hat{\circ}$ & \begin{tabular}{l}
$\underset{N}{N}$ \\
\hdashline
\end{tabular} & 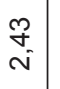 \\
\hline ल) & \begin{tabular}{|l} 
L \\
O \\
0 \\
0
\end{tabular} & $\frac{g}{0}$ & $\mid \begin{array}{c}\mathscr{j} \\
0 \\
0\end{array}$ & $\begin{array}{l}f \\
0 \\
0\end{array}$ & $\begin{array}{l}0 \\
\stackrel{0}{0} \\
0\end{array}$ & \pm & مٌ & $\nabla$ & $\left|\begin{array}{l}0 \\
0 \\
0 \\
0\end{array}\right|$ & $\begin{array}{l}\stackrel{\mathscr{N}}{0} \\
\stackrel{0}{0}\end{array}$ & $\begin{array}{l}\delta_{0} \\
0\end{array}$ & $\begin{array}{l}\mathscr{Q} \\
\stackrel{\circ}{0}\end{array}$ & $E_{0}^{E}$ & $\begin{array}{l}\infty \\
\stackrel{\infty}{0} \\
0\end{array}$ & $\begin{array}{l}8 \\
\& \\
0\end{array}$ & $\begin{array}{l} \pm \\
\stackrel{0}{0} \\
0^{-}\end{array}$ & \begin{tabular}{l}
\multirow{J}{*}{} \\
$\stackrel{0}{*}$
\end{tabular} & $\begin{array}{l}\underset{0}{0} \\
\underset{0}{n}\end{array}$ & $\begin{array}{l}\text { पे } \\
0 \\
0 \\
0\end{array}$ & & & 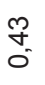 & $\begin{array}{l}\bar{\delta} \\
0 \\
0\end{array}$ \\
\hline
\end{tabular}

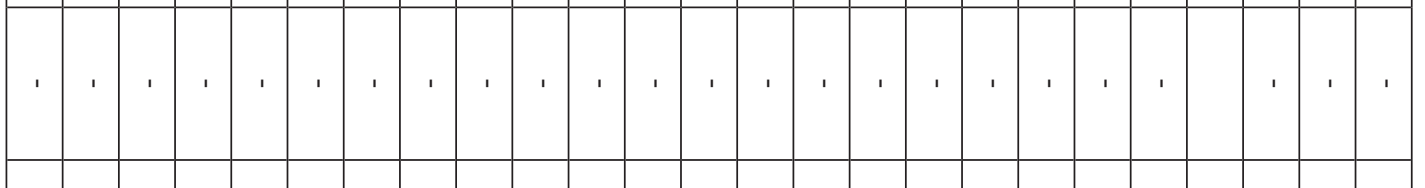

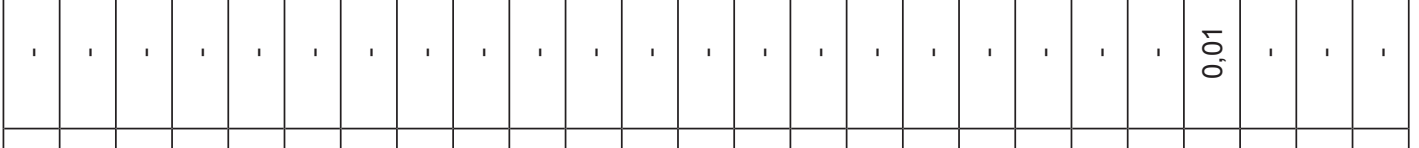

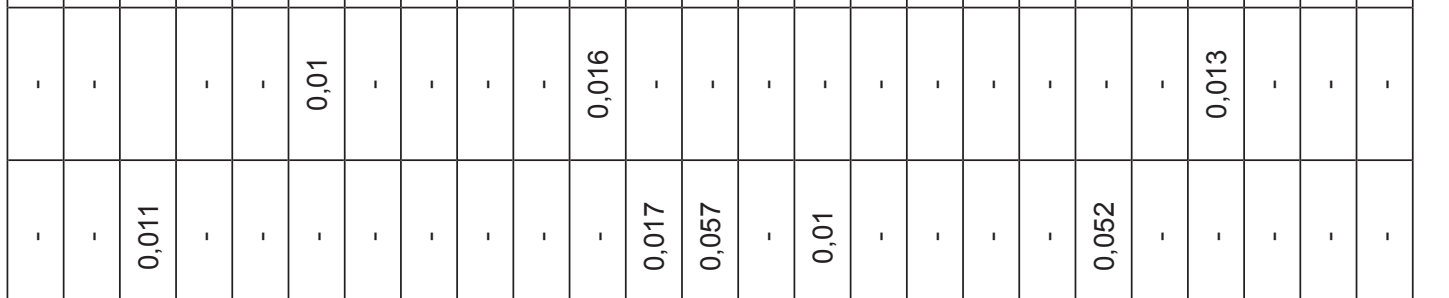

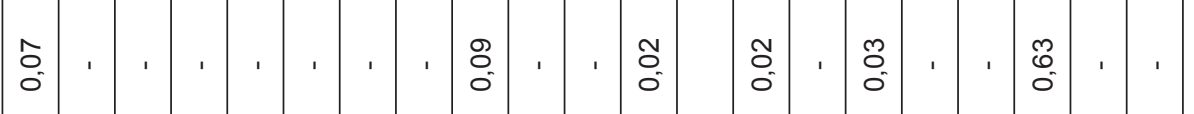

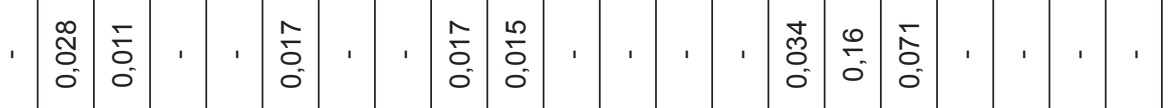

$\stackrel{m}{\stackrel{m}{c}}$

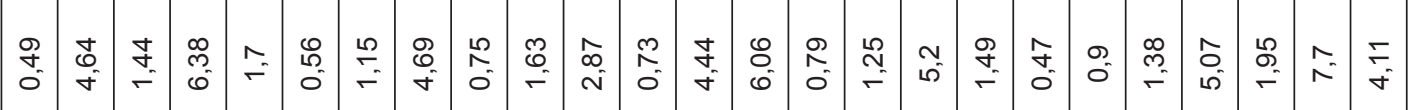

\&

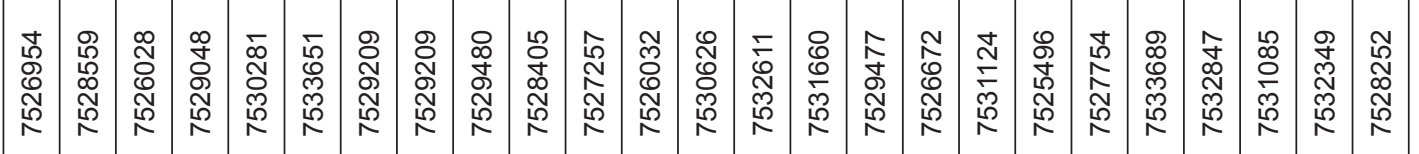

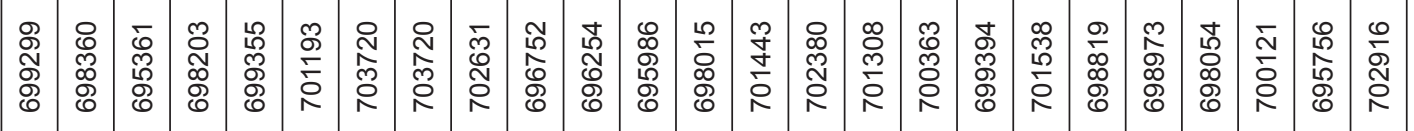

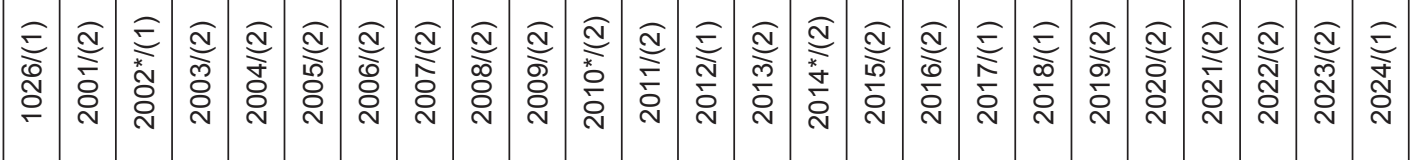




\begin{tabular}{|c|c|c|c|c|c|c|c|c|c|c|}
\hline \multirow{4}{*}{ 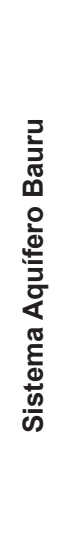 } & 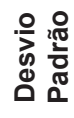 & $\begin{array}{l}8 \\
0 \\
0\end{array}$ & $\begin{array}{l}\bar{N} \\
\text { o }\end{array}$ & $\begin{array}{l}\mathbb{N} \\
\tilde{O}\end{array}$ & 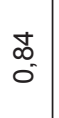 & $\begin{array}{l}0 \\
0 \\
0\end{array}$ & $\begin{array}{l}\mathbf{0} \\
0^{-}\end{array}$ & $\begin{array}{l}\bar{\tau} \\
\tilde{o}\end{array}$ & $\stackrel{\underset{S}{N}}{\leftarrow}$ & 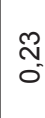 \\
\hline & 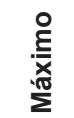 & $\stackrel{\hat{N}}{N}$ & $\begin{array}{l}\stackrel{R}{R} \\
\text { o } \\
\text { - }\end{array}$ & $\begin{array}{l}\bar{\sigma} \\
\bar{j} \\
\bar{m}\end{array}$ & $\begin{array}{l}8 \\
8 \\
0\end{array}$ & $\begin{array}{l}8 \\
\stackrel{5}{N}\end{array}$ & $\begin{array}{l}\bar{N} \\
0\end{array}$ & $\begin{array}{l}L_{0}^{\circ} \\
\omega^{\circ}\end{array}$ & 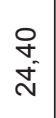 & \\
\hline & $\begin{array}{l}\frac{\pi}{0} \\
\stackrel{\frac{\pi}{\pi}}{\Sigma}\end{array}$ & $\frac{m}{6}$ & \begin{tabular}{l} 
o \\
s \\
\multirow{N}{*}{}
\end{tabular} & $\begin{array}{l}\stackrel{8}{ } \\
\stackrel{6}{\leftarrow} \\
\leftarrow\end{array}$ & $\begin{array}{l}\circ \\
\stackrel{N}{N}\end{array}$ & $\begin{array}{l}\ddot{B} \\
\stackrel{\sim}{\sim}\end{array}$ & $\stackrel{\stackrel{g}{\circ}}{\circ}$ & $\underset{⿱}{\stackrel{*}{*}}$ & $\stackrel{\hat{N}}{\digamma}$ & \\
\hline & 胥 & $\begin{array}{l}\text { N } \\
\text { [5 }\end{array}$ & $\frac{8}{\infty}$ & 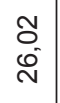 & \begin{tabular}{l}
$\stackrel{0}{2}$ \\
\multirow{\sigma}{*}{}
\end{tabular} & $\begin{array}{l}\hat{L} \\
0 \\
0\end{array}$ & $\begin{array}{l}q \\
q \\
0\end{array}$ & 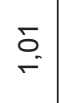 & $\mid$\begin{tabular}{l}
0 \\
\multirow{2}{*}{} \\
0
\end{tabular} & \\
\hline \multicolumn{2}{|c|}{ ג ג } & $\frac{I}{2}$ & 岦 & 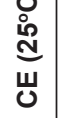 & $\begin{array}{l}\text { Oீ } \\
\text { I0 }\end{array}$ & ల్ల & in & \pm & 妾 & \\
\hline
\end{tabular}

亮

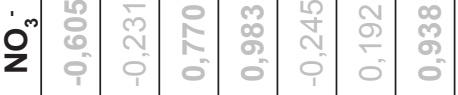

న్

के

$\stackrel{+\pi}{2}$

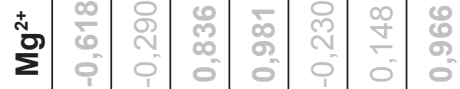

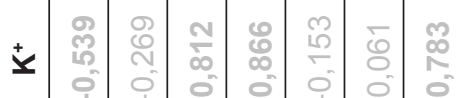

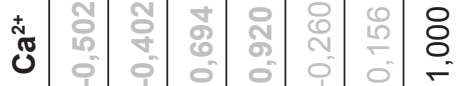

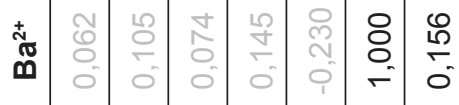

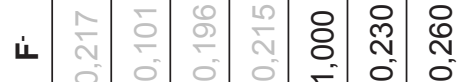

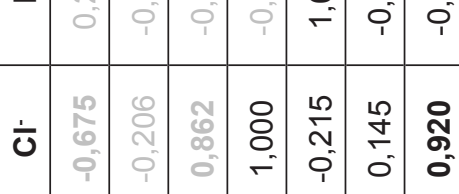

की

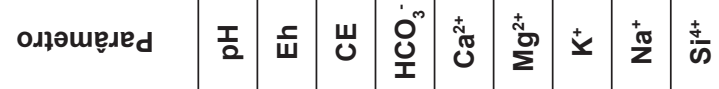

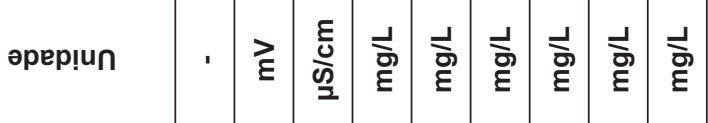

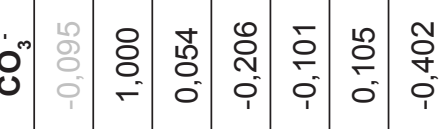

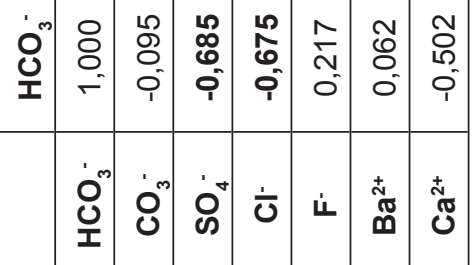




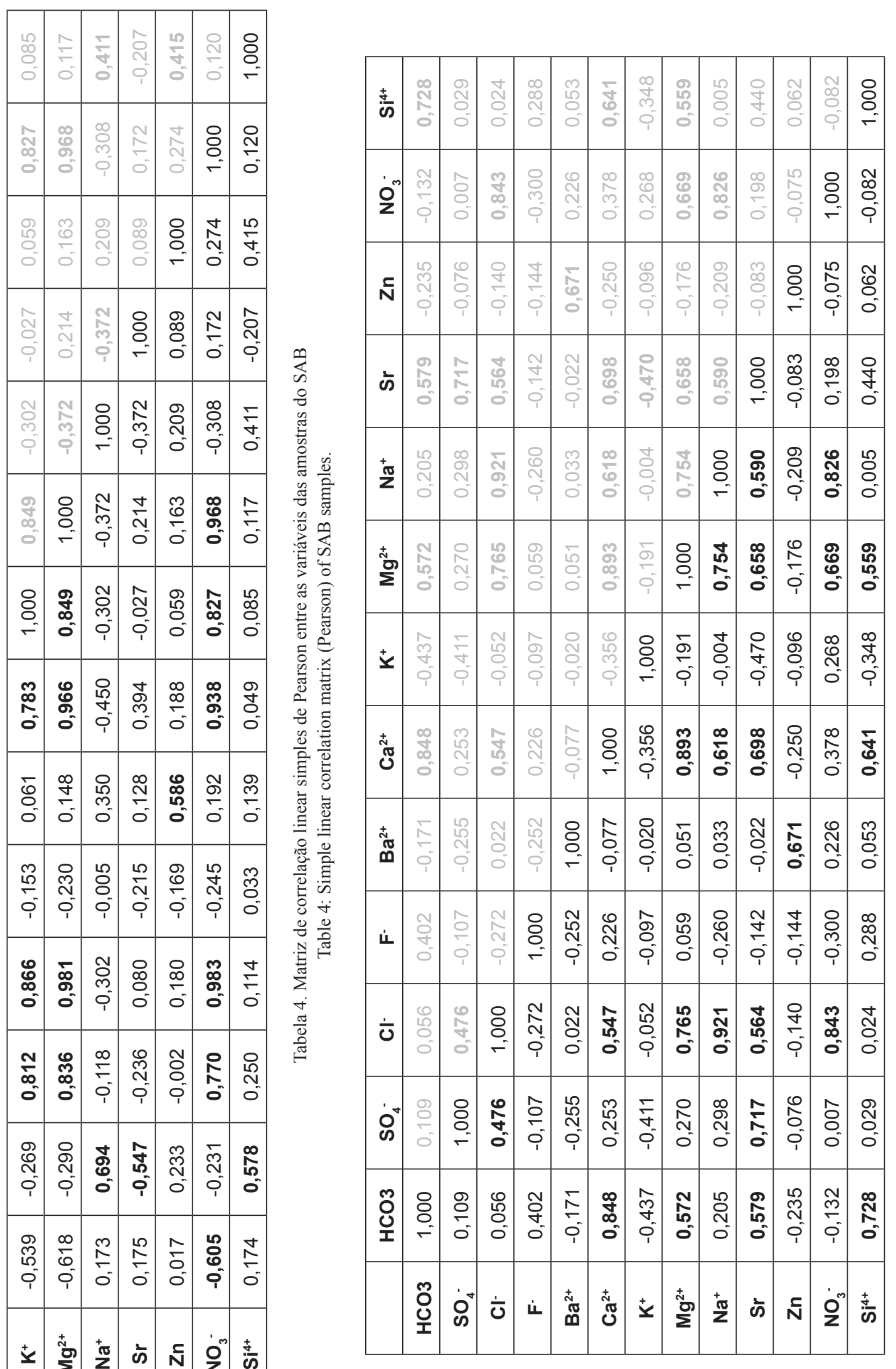


Tabela 5. Índice de saturação de calcita, quartzo e calcedônia das amostras Table 05 . Saturation index of calcite, quartz and chalcedony of water samples.

\begin{tabular}{|c|c|c|c|c|c|c|c|}
\hline Amostra & $\begin{array}{l}\text { IS } \\
\text { Calcita }\end{array}$ & $\begin{array}{c}\text { IS } \\
\text { Quartzo }\end{array}$ & $\begin{array}{l}\text { IS } \\
\text { Calcedônia }\end{array}$ & Amostra & $\begin{array}{l}\text { IS } \\
\text { Calcita }\end{array}$ & $\begin{array}{c}\text { IS } \\
\text { Quartzo }\end{array}$ & $\begin{array}{l}\text { IS } \\
\text { Calcedônia }\end{array}$ \\
\hline $1001 /(1)$ & $-0,01$ & 0,03 & $-0,4$ & $1026 /(1)$ & 0,15 & 0,02 & $-0,41$ \\
\hline $1002 /(1)$ & 0,06 & 0,01 & $-0,42$ & $2001 /(2)$ & $-3,97$ & 0,21 & $-0,22$ \\
\hline $1003 /(1)$ & $-0,41$ & 0,04 & $-0,39$ & $2002^{*} /(1)$ & $-2,1$ & 0,12 & $-0,31$ \\
\hline $1004^{*} /(1)$ & $-0,15$ & 0,05 & $-0,38$ & $2003 /(2)$ & $-2,3$ & 0,3 & $-0,13$ \\
\hline $1005 /(1)$ & 0,23 & $-0,04$ & $-0,47$ & $2004 /(2)$ & $-1,45$ & 0,32 & $-0,11$ \\
\hline $1006 /(1)$ & 0,14 & 0 & $-0,43$ & $2005 /(2)$ & $-3,99$ & 0,05 & $-0,38$ \\
\hline $1007 /(1)$ & $-0,22$ & $-0,06$ & $-0,49$ & $2006 /(2)$ & $-2,51$ & 0,25 & $-0,18$ \\
\hline $1008 /(1)$ & $-0,06$ & 0,03 & $-0,4$ & $2007 /(2)$ & $-1,12$ & 0,43 & 0,01 \\
\hline $1009 * /(1)$ & 0,05 & 0,03 & $-0,39$ & $2008 /(2)$ & $-1,66$ & 0,34 & $-0,09$ \\
\hline $1010 /(2)$ & $-1,95$ & 0,26 & $-0,17$ & $2009 /(2)$ & $-4,16$ & 0,05 & $-0,37$ \\
\hline $1011 /(1)$ & $-2,9$ & 0,16 & $-0,27$ & $2010 * /(2)$ & $-4,66$ & 0,1 & $-0,33$ \\
\hline $1012 /(1)$ & $-1,12$ & 0,15 & $-0,28$ & $2011 /(2)$ & $-3,22$ & 0,23 & $-0,2$ \\
\hline $1013 /(1)$ & $-0,37$ & 0,05 & $-0,38$ & $2012 /(1)$ & $-1,8$ & 0,17 & $-0,26$ \\
\hline $1014 /(1)$ & $-0,99$ & 0,01 & $-0,42$ & $2013 /(2)$ & $-3,07$ & 0,15 & $-0,28$ \\
\hline $1015 /(1)$ & $-0,16$ & 0,07 & $-0,36$ & $2014^{*} /(2)$ & $-2,34$ & 0,19 & $-0,24$ \\
\hline $1016 /(1)$ & $-0,11$ & 0,01 & $-0,42$ & $2015 /(2)$ & $-3,68$ & 0,21 & $-0,21$ \\
\hline $1017 /(1)$ & $-0,1$ & $-0,02$ & $-0,45$ & $2016 /(2)$ & $-3,24$ & 0,18 & $-0,25$ \\
\hline $1018 /(1)$ & 0,02 & $-0,03$ & $-0,46$ & $2017 /(1)$ & $-0,06$ & $-1,19$ & $-1,61$ \\
\hline $1019 /(1)$ & 0,12 & $-0,16$ & $-0,59$ & $2018 /(1)$ & $-1,4$ & 0,12 & $-0,31$ \\
\hline $1020 /(1)$ & 0,08 & $-0,18$ & $-0,61$ & $2019 /(2)$ & $-3,84$ & 0,16 & $-0,26$ \\
\hline $1021 /(1)$ & 0,2 & $-0,15$ & $-0,58$ & $2020 /(2)$ & $-1,98$ & 0,24 & $-0,19$ \\
\hline $1022 /(1)$ & 0,19 & $-0,07$ & $-0,5$ & $2021 /(2)$ & $-3,92$ & 0,15 & $-0,28$ \\
\hline $1024 /(1)$ & 0,2 & $-0,07$ & $-0,5$ & $2022 /(2)$ & $-2,88$ & 0,1 & $-0,33$ \\
\hline \multirow[t]{2}{*}{$1025 /(1)$} & 0,32 & $-0,07$ & $-0,5$ & $2023 /(2)$ & $-2,02$ & 0,13 & $-0,3$ \\
\hline & & & & $2024 /(1)$ & $-0,15$ & $-1,14$ & $-1,57$ \\
\hline
\end{tabular}

(1): Aquífero Guarani; (2): Aquifero Bauru

Já as águas do SAB têm como íons predominantes: $\mathrm{rHCO}_{3}^{-}>\mathrm{rNO}_{3}^{-}>\mathrm{rCl}^{-}$, para os ânions, e $\mathrm{rCa}^{2+}>$ $\mathrm{rMg}^{2+}>\mathrm{rNa}^{+}>\mathrm{rK}^{+}>\mathrm{rBa}^{2+}$, para os cátions (Figura 5).

Os diagramas de estabilidade (Figura 6) elaborados com os resultados das análises das águas aqui estudadas indicam que o equilíbrio químico das amostras do SAB está no campo das caulinitas, enquanto que o equilíbrio químico das amostras do SAG está no campo das montmorilonitas. As concentrações de sódio e cálcio no SAG (Tabela 3) apresentam correlação negativa e do cálcio com bicarbonato no SAB (Tabela 4), correlação positiva.

Nas amostras 1004, 1009, 2002 e 2009, que foram coletadas de poços instalados no SAG, observam-se maiores concentrações de cálcio, quando comparados às demais amostras do SAG. Verifica-se ainda que as amostras 2002 e 2012 apresentam altas concentrações de cloreto e nitrato, comparáveis a concentrações obtidas em alguns poços instalados no SAB.

\section{DISCUSSÃO DOS RESULTADOS}

\section{Sistema Aquífero Guarani}

A baixa correlação entre os íons cálcio e bicarbonato (Tabela 3) e o índice de saturação da calcita próximo do equilíbrio em amostras do SAG (Tabela 5, Figura 7 A), indicam precipitação desse mineral. No equilíbrio em sistemas abertos (aquífero livre), a pressão de $\mathrm{CO}_{2}$ é constante, com aporte contínuo devido à presença de $\mathrm{CO}_{2}$ na atmosfera e à degradação de matéria orgânica na zona vadosa. Em sistemas fechados (aquífero confinado), a pressão de $\mathrm{CO}_{2}$ tende a ser menor (DREVER, 1996), o que diminui a solubilidade da calcita e resulta em sua menor concentração na água.

Já a maior concentração de bicarbonato pode estar balanceada, conformejá mencionado por Meng e Maynard(2001), comdissoluçãodefeldspatoalcalino, segundoasequações 1 e2:

$2 \mathrm{KAlSi}_{3} \mathrm{O}_{8}$ (Feldspato Potássico) $+2 \mathrm{CO}_{2}+11 \mathrm{H}_{2} \mathrm{O}=$ $\mathrm{Al}_{2} \mathrm{Si}_{2} \mathrm{O}_{5}(\mathrm{OH})_{4}$ (Caulinita) $+2 \mathrm{~K}^{+}+4 \mathrm{H}_{4} \mathrm{SiO}_{4}+2 \mathrm{HCO}_{3}$ [1] 
$2 \mathrm{NaAlSi}_{3} \mathrm{O}_{8}($ Albita $)+2 \mathrm{CO}_{2}+11 \mathrm{H}_{2} \mathrm{O}=$

$\mathrm{Al}_{2} \mathrm{Si}_{2} \mathrm{O}_{5}(\mathrm{OH})_{4}$ (Caulinita) $+2 \mathrm{Na}^{+}+4 \mathrm{H}_{4} \mathrm{SiO}_{4}+2 \mathrm{HCO}_{3}^{-}$ [2]

Considerando essas reações, a razão iônica obtida para as amostras do SAG (Figuras 4 e 5) é característica de águas intermediárias a confinadas, segundo estudos de SILVA (1983), MENG E MAYNARD (2001) E GASTMANS (2007) para esse sistema aquífero.

A correlação de Pearson de $-0,45$ (Tabela 5), entre o cálcio e o sódio no $\mathrm{SAG}$, pode ser resultado de troca catiônica (Equação 3), conforme sugerido em Meng e Maynard (2004), Sracek e Hirata (2002) e Silva (1983).

$\mathrm{Ca}^{2+}+\mathrm{Na}_{2}-\mathrm{X}=2 \mathrm{Na}^{+}+\mathrm{Ca}-\mathrm{X}$

[3]

(onde X corresponde ao sítio catiônico).

Os diagramas de equilíbrio mostram que as águas do SAG, na área de estudo, encontram-se predominantemente no campo de estabilidade das montmorilonitas (Figura 6), indicando longo tempo de residência da água subterrânea, com baixa lixiviação de sílica e cátions durante a hidrólise do feldspato em argilominerais. Já as amostras situadas no campo de estabilidade da caulinita, próximas ao campo de estabilidade do microclínio, indicam ocorrência de reações
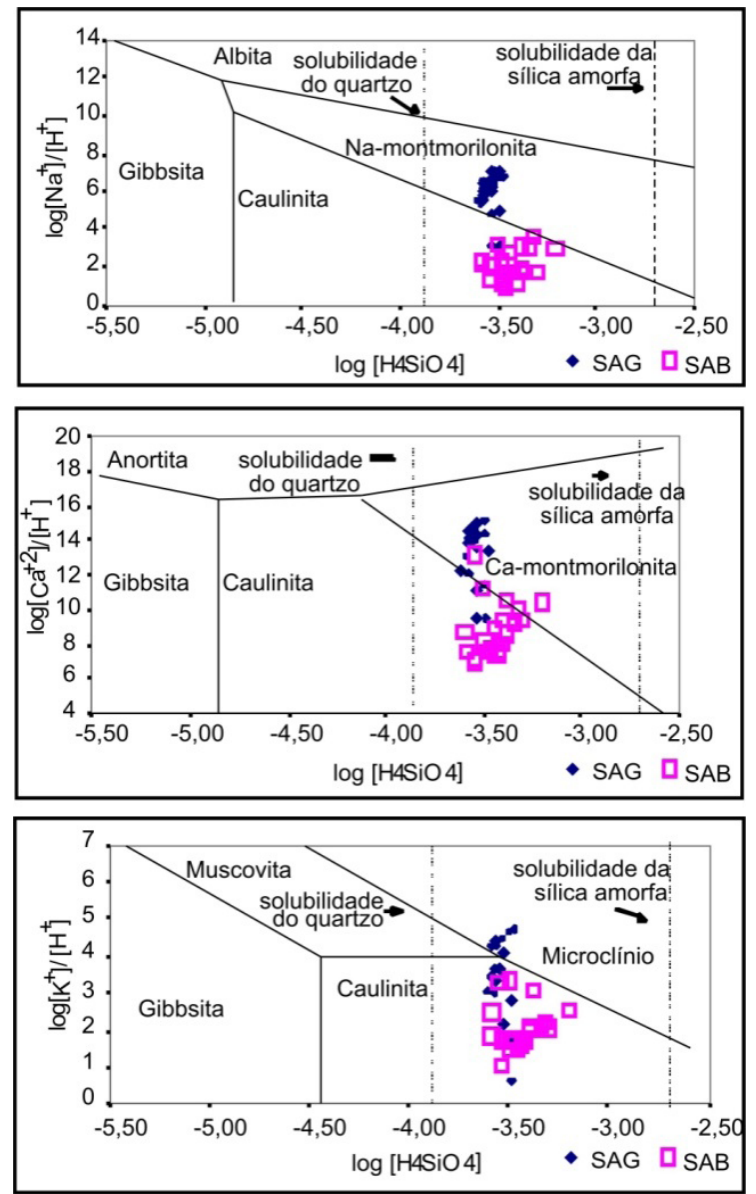

Águas Subterrâneas, v.24, n.1, p.69-84, 2010 de hidrólise a partir da alteração do feldspato potássico.

Esses resultados são compatíveis com a composição mineralógica dos arenitos do SAG. Minerais detríticos, como feldspato, e autigênicos como a esmectita (GESICKI, 2007), e minerais autigênicos, como montmorilonita (CAETANO-CHANG, 1997), foram identificados em amostras de arenitos do SAG.

Esses dados indicam que os processos determinantes na composição hidroquímica do SAG, na área de estudo, são os de hidrólise (bissialitização) e dissolução/precipitação, em condições de maior grau de confinamento, sem recarga meteórica direta (sistema fechado). A disponibilidade de $\mathrm{CO}_{2}$, proveniente do ar ou da degradação de matéria orgânica, é menor ou ausente, o pH é básico e a calcita apresenta-se saturada, tal como observado em águas subterrâneas de sistemas fechados, com pH básico e baixa pressão de gás carbônico (STRADIOTO, 2007; GASTMANS, 2008), favorecendo a saturação em calcita. A origem do sódio pode ter relação com a alteração de feldspatos ou com troca catiônica do sódio pelo cálcio nos argilominerais, como sugerido por Silva (1983) e Sracek e Hirata (2002).

Em relação ao nitrato, as maiores concentrações no SAG ocorrem associadas aos íons sulfato, cloreto, cálcio, potássio e magnésio e a valores menores de $\mathrm{pH}$ (Tabela 3). A presença de nitrato não tem relação com o substra-

Figura 6. Diagramas de estabilidade $\mathrm{NaO}-\mathrm{Al}_{2} \mathrm{O}_{3}-\mathrm{SiO}_{2}-\mathrm{H}_{2} \mathrm{O}$ $\left(25^{\circ} \mathrm{C}\right) ; \mathrm{CaO}-\mathrm{Al}_{2} \mathrm{O}_{3}-\mathrm{SiO}_{2}-\mathrm{H}_{2} \mathrm{O}\left(25^{\circ} \mathrm{C}\right)$ e $\mathrm{K}_{2} \mathrm{O}-\mathrm{Al}_{2} \mathrm{O}_{3}-\mathrm{SiO}_{2}-\mathrm{H}_{2} \mathrm{O}$ $\left(25^{\circ} \mathrm{C}\right)$.

Figure 6. Phase diagram: $\mathrm{NaO}-\mathrm{Al}_{2} \mathrm{O}_{3}-\mathrm{SiO}_{2}-\mathrm{H}_{2} \mathrm{O}\left(25^{\circ} \mathrm{C}\right)$; $\mathrm{CaO}-$ $\mathrm{Al}_{2} \mathrm{O}_{3}-\mathrm{SiO}_{2}-\mathrm{H}_{2} \mathrm{O}\left(25^{\circ} \mathrm{C}\right)$ e $\mathrm{K}_{2} \mathrm{O}-\mathrm{Al}_{2} \mathrm{O}_{3}-\mathrm{SiO}_{2}-\mathrm{H}_{2} \mathrm{O}\left(25^{\circ} \mathrm{C}\right)$.

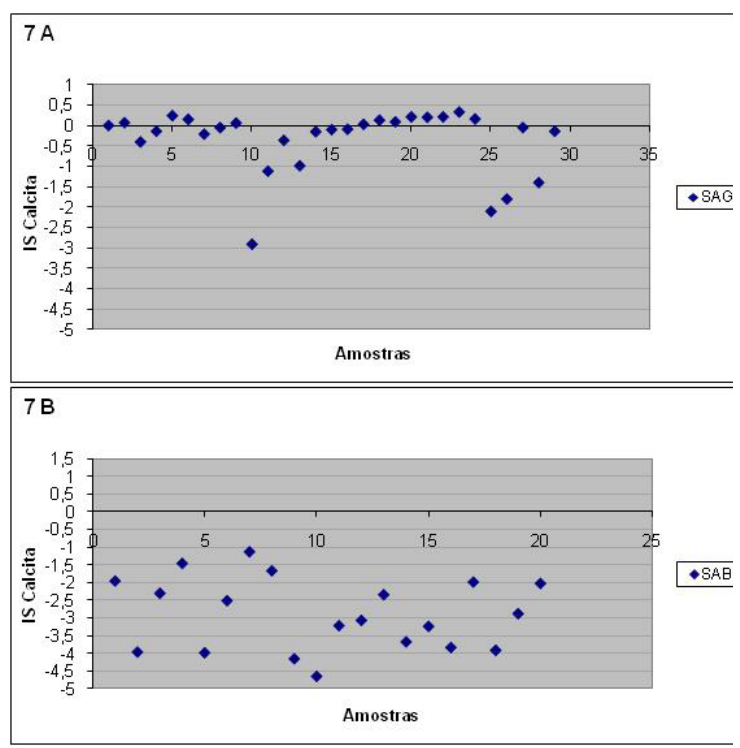

Figura 7. Gráfico do índice de saturação de calcita para amostras do SAG (7A) e SAB (7B).

Figure 7. Saturation index of calcite - SAG (7A) and SAB (7B) 
to rochoso do SAG, e pode indicar aporte por origem antrópica, principalmente quando considerada sua associação com sulfato, cloreto e nitrato. Esta situação pode ser explicada pela interconexão de águas deste sistema aquífero com as do sistema aquífero sobreposto - SAB.

\section{Sistema Aquífero Bauru}

A razão iônica dos cátions (Figuras 5) é coerente com a obtida para o Sistema Aquífero Bauru por DAEE (1976), NA REGIÃO DE BAURU, E POR BARISON (2003), em áreas de ocorrência da Formação Marília. Com relação aos ânions, não foram verificadas, nesses trabalhos, concentrações significativas de nitrato e cloreto de forma disseminada.

A correlação positiva entre $\mathrm{Ca}^{2+}$ e $\mathrm{HCO}_{3}^{-}$(Tabela 4) e a insaturação das águas do SAB (Tabela 5, Figura 7 B) em relação à calcita sugerem que a fonte desses íons pode estar relacionada à dissolução da calcita presente em algumas porções das formações Adamantina e Marília (Equação 4).

$$
\mathrm{CaCO}_{3}+\mathrm{CO}_{2}+\mathrm{H}_{2} \mathrm{O}=\mathrm{Ca}^{2+}+2 \mathrm{HCO}_{3}^{-}
$$

[4]

Esse fato, associado ao equilíbrio químico das amostras no campo das caulinitas (Figura 6), indica que os processos principais que afetam a composição hidroquímica das águas do SAB são: hidrólise (monossialitização), com neoformação de oxi-hidróxidos e caulinita, e dissolução de minerais.

$\mathrm{O}$ baixo $\mathrm{pH}$ das águas do SAB e a insaturação em calcita e calcedônia são condizentes com características de aquíferos em sistemas abertos. As águas meteóricas, ácidas e de baixa condutividade elétrica, que percolam rochas de formações superficiais, infiltram-se nessas rochas e reagem com minerais detríticos, tais como feldspatos. A hidrólise de minerais silicáticos libera sílica e cátions, com neoformação/substituição de óxidos, hidróxidos e argilominerais. Já com os minerais carbonáticos ocorre processo de dissolução, com liberação de íons carbonato e cálcio. Os produtos minerais da neoformação e a constituição hidroquímica da água estão associados ao tempo de residência da água no meio e à disponibilidade de íons.

Segundo Giafferis e Oliveira (2006), as maiores concentrações de nitrato ocorrem associadas aos íons cloreto, magnésio e sódio, a maiores valores de condutividade elétrica (Tabela 4), que podem ter relação com a grande densidade demográfica, e à presença de fossas sépticas e tubulações de esgoto antigas. Assim, as maiores concentrações de sódio, observadas em algumas amostras, tais como 2010 e 2014, que são bicarbonatadas sódicas, podem estar relacionadas a fontes antrópicas, como o nitrato e o cloreto. Nesse caso, a maior vulnerabilidade do SAB está relacionada à sua maior proximidade com a fonte primária dos contaminantes (antigas tubulações de esgoto).

\section{REFERÊNCIAS BIBLIOGRÁFICAS} AGÊNCIA NACIONAL DE AGUAS - ANA. Atlas Brasil: Abastecimento urbano de água:
Nota-se ainda que as características hidroquímicas distintas das amostras do SAB em relação ao SAG indicam ausência de mistura significativa entre ambos. Essa separação tem origem provável na presença de porções argilosas, principalmente na base da Formação Adamantina, conforme observado em perfis geofísicos por Cavaguti e Paula e Silva (1994), que atuam como camada isolante.

\section{CONCLUSÕES}

As unidades litoestratigráficas que constituem os sistemas aquíferos Guarani e Bauru estão em contato direto, discordante e erosivo, na maior parte da área urbana de Bauru, onde não ocorre a Formação Serra Geral.

A caracterização hidroquímica desses dois sistemas aquíferos, para a avaliação de possível interconexão entre o SAG e SAB, baseou-se nos resultados analíticos de amostras de água subterrânea coletadas em poços tubulares explorados no município de Bauru.

As águas do SAG estão predominantemente em equilíbrio químico com montmorilonitas, apresentam saturação em calcita, possuem como cátion predominante o sódio, que mostra correlação negativa com o cálcio, e são predominantemente básicas. Essas características são concordantes com aquelas descritas por Silva (1983) para as águas do SAG em porções de confinamento moderado.

O SAB apresenta água predominantemente bicarbonatada cálcica, com $\mathrm{pH}$ ácido e presença significativa e disseminada (entre os quatro íons predominantes) de cloreto e nitrato, relacionados à origem antrópica. Essas águas estão predominantemente no campo de estabilidade das caulinitas e apresentam insaturação em carbonatos, características estas comuns em aquíferos livres, com baixo tempo de residência, aporte de $\mathrm{CO}_{2}$ (proveniente da atmosfera e da matéria orgânica no solo superficial), $\mathrm{pH}$ ácido, favorecendo lixíviação de minerais por meio de reações congruentes (ex. dissolução de minerais carbonáticos) e incongruentes (ex. hidrólise de minerais feldspáticos). A condutividade elétrica associada às maiores concentrações de nitrato e cloreto nas águas do SAB, em relação às do $\mathrm{SAG}$, é fato provavelmente relacionado à sua maior proximidade com a superfície e à ação antrópica.

Estas diferenças entre as características hidroquímicas dos dois sistemas aquíferos denotam a ausência de mistura significativa entre ambos, provavelmente devido às porções argilosas existentes na base da Formação Adamantina. Contudo, em quatro poços do SAG, o pH e as concentrações de cálcio, nitrato e cloreto são similares aos obtidos para as águas do SAB, denotando que nesses locais os sistemas aquíferos estão interconectados. Tal interconexão pode ser fruto das características de construção dos poços, o que ocasionaria contaminação cruzada, com infiltração através do pré-filtro.

Panorama Nacional. Agência Nacional de águas; Engecorps/ Cobrape, Brasília, 2010, $2 \mathrm{v}$. 
BARISON, M.R. Estudo Hidroquímico na Porção Meridional do Sistema Aquífero Bauru no Estado de São Paulo. 2003. 153 p. Tese (Doutorado em Geociências e Meio Ambiente) - Instituto de Geociências e Ciências Exatas, Universidade Estadual Paulista, Rio Claro, 2003.

CAETANO-CHANG, M.R. A Formação Pirambóia no centro-leste do estado de São Paulo. 1997. 196p. Tese (Livre Docência em Geologia) - Instituto de Geociências e Ciências Exatas, Universidade Estadual Paulista, Rio Claro, 1997.

CAMPOS, H.C.N.S. Contribuição ao estudo hidrogeoquímico do Grupo Bauru no estado de São Paulo. 1987. 105 p. Dissertação (Mestrado em Geociências) - Instituto de Geociências, Universidade de São Paulo, São Paulo, 1987.

CAVAGUTI, N.; PAUlA E SILVA, F. Gestão dos recursos hídricos subterrâneos na cidade de Bauru - SP, face às características hidrogeológicas especiais da região. In: CONGRESSO BRASILEIRO DE ÁGUAS SUBTERRÂNEAS. n. 7, 1992, Recife. Anais... Recife: ABAS, 1994. p. 74-79. COELHO, R.O. Estudo hidroquímico e isotópico do Aquífero Bauru, sudoeste do estado de São Paulo. 1996. 103 p. Dissertação (Mestrado em Recursos Minerais e Hidrogeologia) - Instituto de Geociências, Universidade de São Paulo, São Paulo, 1996.

DEPARTAMENTO DE ÁGUAS E ENERGIA ELÉTRICA - DAEE. Estudo de águas subterrâneas: regiões administrativas 7,8 e 9 Bauru, São José do Rio Preto e Araçatuba - SP, São Paulo: ENCO, 1976, 4 v.

DONATTI L.M., SAWAKUCHI A.O., GIANNINI P.C.F., FERNANDES L.A. The Pirambóia-Botucatu sucession (Late Permian-Early Cretaceous, Paraná Basin, São Paulo and Paraná States): two contrasting eolian systems. Anais da Academia Brasileira de Ciências, v. 73, n. 3, p. 465, 2001.

DREVER, J.I. The geochemistry of natural waters: surface and groundwater environments. 3rd. ed. Upper Saddle River: Prentice Hall, 1997. 436 p.

FERNANDES, L.A.. A cobertura cretácea suprabasaltica no Paraná e Pontal do Paranapanema (SP): os grupos Bauru e Caiuá. 1992. 192 p. Dissertação (Mestrado em Geociências) - Instituto de Geociências, Universidade de São Paulo, São Paulo, 1992.

FERNANDES, L.A. Estratigrafia e evolução geológica da parte oriental da Bacia Bauru (Ks, Brasil). 1998. 216 p. Tese (Doutorado em Geociências) - Instituto de Geociências, Universidade de São Paulo, São Paulo, 1998.

GASTMANS, D. Hidrogeologia e hidroquímica do sistema aquífero Guarani na porção ocidental da Bacia Sedimentar do Paraná. 2007. 197 p. Tese (Doutorado em Geociências e Meio Ambiente) - Instituto de Geociências e Ciências Exatas, Universidade Estadual Paulista, Rio Claro, 2007.
GESICKI, A.L.D. Evolução diagenética das formações Pirambóia e Botucatu (Sistema Aquífero Guarani) no estado de São Paulo. 2007. 175 p. Tese (Doutorado em Geociências) - Instituto de Geociências, Universidade de São Paulo, São Paulo, 2007.

GIAFFERIS, G. P.; OLIVEIRA, E.L. Gestão da Qualidade das Águas Subterrâneas pela Autarquia $\mathrm{Mu}-$ nicipal de Água no Município de Bauru - SP. In: Simpósio Brasileiro de Recursos Hídricos. n. 17. São Paulo, 2007, Anais...São Paulo: ABRH, 2007.

GIAFFERIS, G.P.; OLIVEIRA, E.L. Investigação da Qualidade das Águas Subterrâneas do Município de Bauru. In: Congresso Brasileiro de Águas Subterrâneas, n. 14, Curitiba, 2006. Anais...Curitiba: ABRH, 2006. INSTITUTO BRASILEIRO DE GEOGRAFIA E ESTATISTICA - IBGE. 2007. URL: www.ibge.org.br. IPCC. Climate Change and Water. Bates, BC, ZW Kundzewicz, S. Wu and JP Palutikof, Eds. Secretariat, Genebra, 210 pp. IPCC Secretariat, Geneva, 210 pp. Junho 2008 June 2008.

MENG, S.X.; MAYNARD, J.B. Use os statistical analysis to formulate conceptual models of geochemical behavior: water chemical data from the Botucatu aquifer in São Paulo state, Brazil. Journal of Hydrology, Amsterdam, v. 250, p. 78-97, 2001.

PARKHURST, D.L.; APPELO, C.A.J. User's guide to PHREEQC (Version 2) - A computer program for speciation, batch-reaction, one-dimensional transport, and inverse geochemical calculations. Denver: U.S. Geological Survey Water-Resources Investigations Report 99-4259, 1999. 310 p.

PAULA E SILVA F. Geologia de subsuperfície e hidroestratigrafia do Grupo Bauru no estado de São Paulo. 2003. Tese (Doutorado em Geociências e Meio Ambiente) - Instituto de Geociências e Ciências Exatas, Universidade Estadual Paulista, Rio Claro, 166 p.

PAULA E SILVA, F.; CAVAGUTI, N. Nova caracterização estratigráfica e tectônica do Mesozóico na cidade de Bauru - SP. Geociências, Rio Claro, v. 1, p. 83-99, 1994. ROCHA, G.A., BERTACHINI, C., CAMPOS, H.C.N.S. \& CAIXETA, J.B. Tentativa de zoneamento das características hidráulicas e hidroquimicas do Aquifero Bauru. In: Encontro de Geologia e Hidrogeologia: O Grupo Bauru no Estado de São Paulo, 1., 1982. São Paulo. Atas...Sao Paulo: SBG/ABAS SILVA, R.B.G. da. Estudo hidroquímico e isotópico das águas subterrâneas do aquífero Botucatu no estado de São Paulo. 1983. 133 p. Tese (Doutorado em Geologia Geral e de Aplicação) - Instituto de Geociências, Universidade de São Paulo, São Paulo: 1983. SOARES, P.C. Divisão estratigráfica do Mesozóico no estado de São Paulo. Revista Brasileira de Geociências, São Paulo, v.5, p. 229-251, 1975. SOARES, P.C.; LANDIM, P.M.B.; FÚLFARO, V.J.; 
SOBREIRO NETO A.F. Ensaio de caracterização estratigráfica do Cretáceo no Estado de São Paulo: Grupo Bauru. Revista Brasileira de Geociências, São Paulo, v. 3, p. 177-185. 1980. SRACEK, O.; HIRATA, R. Geochemical and stable isotopic evolution of the Guarani aquifer system in the state of São Paulo, Brazil. Hydrogeology Journal, Reston, v. 10, p. 643-655, 2002.

STRADIOTO, M.R. Hidroquímica e aspectos diagenéticos do sistema aquífero bauru na região sudeste do estado de São Paulo. 2007. 103 p. Dissertação (Mestrado em Geociências e Meio Ambiente) - Instituto de Geociências e Ciências Exatas,
Universidade Estadual Paulista. Rio Claro. 2007. UNESCO. Water in a changing world. The united nations world water development Report 3. UNESCO 2009.

WU, F.T.; CAETANO-CHANG M.R. Estudo mineralógico dos arenitos das formações Pirambóia e Botucatu no centro-leste do estado de São Paulo. Revista Instituto Geológico do Estado do São Paulo. São Paulo, v. 13, p. 58-68, 1992.

\section{AGRADECIMENTOS.}

Os autores agradecem à FAPESP (\# 04/062960) pelo financiamento do projeto e ao CNPq pela concessão de bolsas de estudo e de pesquisa. 